\title{
Design and Characterization of Endostatin-Loaded Nanoparticles for In Vitro Antiangiogenesis in Squamous Cell Carcinoma
}

\author{
Samson A. Adeyemi, Yahya E. Choonara, Pradeep Kumar, Lisa C. du Toit, and Viness Pillay \\ Wits Advanced Drug Delivery Platform Research Unit, Department of Pharmacy and Pharmacology, School of Therapeutic Science, \\ Faculty of Health Sciences, University of the Witwatersrand, Johannesburg, 7 York Road, Parktown 2193, South Africa \\ Correspondence should be addressed to Viness Pillay; viness.pillay@wits.ac.za
}

Received 4 February 2017; Revised 22 March 2017; Accepted 9 April 2017; Published 4 June 2017

Academic Editor: Yan Zou

Copyright (C) 2017 Samson A. Adeyemi et al. This is an open access article distributed under the Creative Commons Attribution License, which permits unrestricted use, distribution, and reproduction in any medium, provided the original work is properly cited.

\begin{abstract}
The aim of this study is to effectively enhance antitumor activities of endostatin by preparing polymeric nanocarriers. NMR and FTIR spectra confirmed the successful grafting of the CHT-g-PEI and CHT-g-PEI-PEG- $\mathrm{NH}_{2}$ conjugates. SEM micrographs confirmed the shape of endostatin-loaded nanoparticles to be spherical while both TEM and zeta size results showed nanoparticle's average size to be $100.6 \mathrm{~nm}$ having a positively charged surface with zeta potential of $7.95 \mathrm{mV}$. The concentrations of CHT and TPP as well as the changing $\mathrm{pH}$ conditions account for the increased swelling pattern of endostatin-loaded nanoparticles and influenced endostatin release in vitro. PEI increased the overall amine protonation while PEG aggravated endostatin encapsulation and release. Nanoparticles swell and release endostatin at acidic tumor $\mathrm{pH}$ of 6.8 compared to physiological $\mathrm{pH}$ of 7.4. The native CHT-gPEI-PEG- $\mathrm{NH}_{2}$ conjugate showed high cytocompatibility above $80 \%$ cell viability across tested formulations. Endostatin-loaded nanoparticles showed a significant reduction in cell viability across tested formulations, with $5.32 \%$ cell death at $125 \mu \mathrm{g} / \mathrm{mL}$ and $13.36 \%$ at $250 \mu \mathrm{g} / \mathrm{mL}$ following 24 hours' incubation period. Interestingly, more than a fourfold (61.68\%) increment in cytotoxicity was observed at nanoparticle concentration of $1000 \mu \mathrm{g} / \mathrm{mL}$. It was concluded that CHT-g-PEI-PEG-NH ${ }_{2}$ is an effective cargo for endostatin delivery with antiangiogenic effect in squamous cell carcinoma.
\end{abstract}

\section{Introduction}

Squamous cell carcinoma (SCC) accounts for different cancer types emanating from various tissues of the body including the skin, oesophagus, head and neck, urinary bladder, prostate, lung, vagina, and cervix resulting in about 2,500 deaths annually in the United States [1]. Over the years, chemoradiation and surgery had been the prominent treatments options for patients diagnosed with SCC. Until recently, with the advent of cutting edge approaches using nanotechnology, chemotherapeutics employed in the management of SCC were hampered with diverse challenges such as suboptimal dosage, cytotoxicity to normal cells due to nontargeted delivery, short circulation time as well as multiple resistances due to the Reticuloendothelial System (RES) [1].

To date, anticancer drugs have been encapsulated into diverse cargos such as polymeric micelles, surfaced-modified particles, liposomes, and nanoparticles for the delivery of anticancer drugs in cancer nanomedicines [2-4] which have not been able to overcome these challenges. Meanwhile, nanoparticles, in contrast to other delivery vehicles, have a number of chemotherapeutic advantages including ease of injection, high drug-loading ratio, reduced toxicity to healthy cells/tissues and enhanced direct targeting effect in both primary and metastatic tumors [2].

Angiogenesis, the formation of new blood vessels, is fundamental to the survival and growth of tumor cells [57]. Recent focus has been on the use of natural and synthetic inhibitors of angiogenesis that can prevent or slow down the growth of tumor cells by blocking the formation of new blood vessels as a promising strategy for tumor therapy [5].

Endostatin is a proteolytic C-terminal fragment of collagen XVIII with a molecular weight of $20 \mathrm{kDa}$. Among other angiogenic inhibitors, endostatin has received the greatest attention for its broad-spectrum and low toxicity [8]. These 
TABLE 1: Box-Behnken experimental design for formulation variables and responses at $\mathrm{pH} 7.4$ and 6.8, respectively.

\begin{tabular}{|c|c|c|c|c|c|c|c|}
\hline \multirow[b]{2}{*}{ Formulation } & \multicolumn{3}{|c|}{ Variables } & \multicolumn{4}{|c|}{ Responses } \\
\hline & $\begin{array}{l}\text { Surfactant conc. } \\
\qquad(\mathrm{mg} / \mathrm{mL})\end{array}$ & $\begin{array}{l}\text { TPP conc. } \\
(\mathrm{mg} / \mathrm{mL})\end{array}$ & $\begin{array}{c}\text { Polymer } \\
\text { conjugate conc. } \\
(\mathrm{mg} / \mathrm{mL})\end{array}$ & $\begin{array}{l}\text { Size } \\
(\mathrm{nm})\end{array}$ & $\begin{array}{l}\text { Surface charge } \\
(\mathrm{mV})\end{array}$ & $\begin{array}{l}\text { Conductivity } \\
(\mathrm{mS} / \mathrm{cm})\end{array}$ & $\begin{array}{l}\text { Polydispersity } \\
\text { index }\end{array}$ \\
\hline $\mathrm{F} 1$ & 1.00 & 0.1 & 1.5 & 65.07 & +16.10 & 0.054 & 0.259 \\
\hline $\mathrm{F} 2$ & 0.10 & 0.1 & 1.5 & 84.22 & +19.80 & 0.079 & 0.367 \\
\hline F3 & 0.10 & 0.2 & 2.5 & 173.9 & +10.40 & 0.056 & 0.689 \\
\hline $\mathrm{F} 4$ & 1.00 & 0.3 & 1.5 & 97.38 & -1.87 & 0.048 & 0.302 \\
\hline F5 & 0.55 & 0.2 & 1.5 & 300.10 & +11.92 & 0.053 & 0.529 \\
\hline F6 & 0.55 & 0.2 & 1.5 & 295.10 & +9.05 & 0.053 & 0.715 \\
\hline F7 & 0.55 & 0.1 & 2.5 & 163.60 & +11.00 & 0.038 & 0.268 \\
\hline F8 & 0.55 & 0.3 & 0.5 & 169.10 & +8.95 & 0.062 & 0.731 \\
\hline F9 & 0.55 & 0.1 & 0.5 & 125.20 & -6.11 & 0.067 & 0.403 \\
\hline $\mathrm{F} 10$ & 1.00 & 0.2 & 2.5 & 125.50 & +0.76 & 0.049 & 1.000 \\
\hline F11 & 0.55 & 0.3 & 2.5 & 56.28 & +9.08 & 0.055 & 1.000 \\
\hline $\mathrm{F} 12$ & 1.00 & 0.2 & 0.5 & 329.10 & -12.30 & 0.052 & 0.788 \\
\hline F13 & 0.10 & 0.2 & 0.5 & 127.21 & -8.94 & 0.057 & 1.000 \\
\hline F14 & 0.10 & 0.3 & 1.5 & 363.10 & -7.63 & 0.062 & 0.408 \\
\hline F15 & 0.55 & 0.2 & 1.5 & 310.20 & +13.10 & 0.048 & 0.550 \\
\hline
\end{tabular}

advantages speed up the investigation process of endostatin into the clinical trial [9]. Endostatin has been shown to inhibit endothelial cell proliferation, migration, and formation of new blood vessels $[7,10]$. However, as any other protein, endostatin has many clinical challenges in its application such as high dosage to maintain its efficacy, high price, short half-life, and instability [11]. As such, incorporation into biodegradable polymers as delivery cargos could ameliorate these limitations.

Chitosan (CHT), as opposed to other naturally occurring polymers and CHT-based nanoparticles, has recently attracted much consideration in both pharmaceutical and biomedical applications due to its exceptional biological properties including biocompatibility, biodegradability, and nontoxicity [12] but with low transfection efficiency. The high buffering potential and transfection efficiency of polyethylenimine (PEI) have been explored for the delivery of DNA and other anticancer therapeutics in the management of cancer diseases [13-15]. Meanwhile, covalent attachment of hydrophilic polyethylene glycol (PEG) onto the surfaces of nanoparticles prolongs the circulation halflife in vivo of encapsulated chemotherapeutics, shields the surface of nanoparticles from uptake by the RES, and reduces carrier's cytotoxicity with improved colloidal stability [16].

In this study, we employed low molecular weight CHT grafted onto PEI as a cationic carrier for improved delivery of endostatin. Furthermore, the surfaces of these grated polymers were coated with PEG to improve endostatin encapsulation and prolong release in vitro. Surface PEGylation of the grafted polymer also enhances its stability in the extracellular matrix of oesophageal squamous cell carcinoma (OSCC) cells. Formulation parameters, optimization and cytocompatibility of the nanosystem were evaluated and the antiangiogenic effect of endostatin-loaded nanoparticles was assessed in an OSCC cell line (KYSE-30).

\section{Materials and Methods}

2.1. Materials. Low molecular weight chitosan (DA $=75-$ $85 \%, M W=50-190 \mathrm{kDa}$ ), branched polyethylenimine (PEI) (Molecular weight $\mathrm{Mw}=25 \mathrm{KDa}$ ), Bovine Serum Albumin (BSA) $(\mathrm{MW}=66 \mathrm{kDa})$, human recombinant endostatin (MW = $22 \mathrm{kDa}$ ), 1-ethyl-3-(3-dimethylaminopropyl) carbodiimide hydrochloride (EDC), N-hydroxysuccinimide (NHS), sodium tripolyphosphate (TPP) $(\mathrm{MW}=367.86 \mathrm{~g} / \mathrm{mol})$, poly (vinyl alcohol) (PVA) $(\mathrm{MW}=85,000 \mathrm{~g} / \mathrm{mol})$, tricholroacetic acid (TCA), and acetonitrile (ACN) were purchased from Sigma-Aldrich Co., Ltd. (St. Louis, MO, USA). Functionalized poly(ethylene) glycol $\left(\mathrm{NH}_{2}-\mathrm{PEG}-\mathrm{COOH}, \mathrm{Mw}=\right.$ $2100 \mathrm{~g} / \mathrm{mol}$ ) was from NANOCS (New York, NY, USA). Cell lines KYSE-30, RPMI, HAM's F12, Fetal Bovine Serum (FBS), and pentamycin/streptomycin were from Life Bioscience (Oakleigh, VIC, Australia). All other solvents and reagents were of analytical grade unless stated otherwise.

\subsection{Preparation of [CHI-g-PEI-PEG-NH $\left.\mathrm{H}_{2}\right]$-Endostatin- Loaded Nanoparticles}

2.2.1. Synthesis of the CHI-g-PEI Conjugate. A Box-Behnken experimental design was employed to generate fifteen nanoformulations as presented in Table 1. A modified method described by Gao et al. [17] was employed to synthesize the CHT-g-PEI conjugate. Briefly, 0.5, 1.5, and $2.5 \mathrm{mg} / \mathrm{mL}$ chitosan (CHT) solutions were prepared in $0.5 \%$ acetic acid and left overnight (Table 1). 1,1-Carbonyldiimidazole (CDI) was added to the CHT solutions and stirred for 1 hour at room temperature to activate the amine group in 
the CHT solution. Subsequently, $0.25 \% \mathrm{v} / \mathrm{v}$ of branched polyethylene imine (PEI) was gently added using a needle and syringe at a molar ratio of CHT amine: PEI concentration of $2: 1$. The reaction mixture was left to polymerize for 24 hours and dialyzed using a dialysis membrane $(\mathrm{MW}=12,000 \mathrm{kDa})$ over double deionized water (DDW) for 24 hours. The final CHT-g-PEI powder was then collected by lyophilization over 24 hours (details of equipment used).

2.2.2. Synthesis of $\mathrm{CHI}-\mathrm{g}-\mathrm{PEI}-\mathrm{PEG}-\mathrm{NH}_{2}$ Conjugate. Copolymer synthesis procedure described by Jiang et al. [18] with modifications was employed in the synthesis of the amino terminal CHT-g-PEI-PEG- $\mathrm{NH}_{2}$ copolymer conjugate following an amide formation reaction between the activated carboxyl groups of $\mathrm{NH}_{2}$-PEG-COOH and the amine groups of CHT-g-PEI as previously described. Briefly, the carboxyl group of the bifunctional PEG $\left(\mathrm{NH}_{2}\right.$-PEG$\mathrm{COOH}$ ) was activated using NHS/EDC chemistry for 15 minutes. Furthermore, the CHT-g-PEI conjugate previously synthesized was gently added to the activated $\mathrm{NH}_{2}$-PEG$\mathrm{COOH}$ solution using a needle and syringe under stirring. The reaction was then allowed to polymerize at $4^{\circ} \mathrm{C}$ and $25^{\circ} \mathrm{C}$ for 12 hours respectively. The synthesized CHT-gPEI-PEG- $\mathrm{NH}_{2}$ conjugate was then dialyzed using a dialysis membrane $(\mathrm{MW}=12,000 \mathrm{kDa})$ against DDW for 48 hours and the dried power was collected by lyophilization over 24 hours.

\subsubsection{Bovine Serum Albumin/Endostatin Entrapment and} Nanoparticle Synthesis. An ionotropic gelation technique was employed for the synthesis of bovine serum albumin or endostatin-loaded nanoparticles comprising the fifteen formulations and the optimized nanosystem, respectively. The fifteen formulations were prepared according to the formulation variables presented in Table 1. For the experimental design formulations, bovine serum albumin (BSA) was employed as a model drug for protein therapeutics for identification of the optimum nanoparticle system into which endostatin would ultimately be loaded. Briefly, $1 \mathrm{mg} / \mathrm{mL}$ BSA solution was mixed with the solution mixture of CHT-gPEI-PEG-NH $\mathrm{N}_{2}$ conjugate under mild stirring for 10 minutes. Varying concentrations of TPP as a cross linker were added drop-wise to the BSA-loaded mixture using a needle and syringe. The formation of an opaque and turbid solution confirmed the formation of the BSA-loaded nanoparticles. Varying concentrations of PVA were also added as surfactant during the nanoparticle synthesis as shown in Table 1. The synthesized nanoparticles were then allowed to undergo gelation for 1 hour under mild stirring and the resultant gel was centrifuged at $5000 \mathrm{rpm}$ for 1 hour. The clear supernatant was discarded and the pellet was resuspended in DDW and refrigerated at $-80^{\circ} \mathrm{C}$. The dried powder BSA/endostatin-loaded nanoparticles were then collected following lyophilization over 24 hours.

2.3. Analysis of Chemical and Functional Transformations via Fourier Transform Infrared Spectroscopy. The vibrational transitions in the chemical structures of CHT-g-PEI,
CHT-g-PEI-PEG-NH ${ }_{2}$, and endostatin-loaded CHT-g-PEIPEG-NH ${ }_{2}$ were evaluated using Fourier transform infrared (FT-IR) spectroscopy (PerkinElmer Inc., Waltham, Massachusetts, USA). Samples were placed on a single bounce diamond crystal and processed by a universal attenuated total reflectance (ATR) polarization accessory, at a resolution of $4 \mathrm{~cm}^{-1}$, with the spectrum ranging from 4000 to $650 \mathrm{~cm}^{-1}$.

2.4. Evaluation of Structural Modifications via Nuclear Magnetic Resonance Spectroscopy. Nuclear Magnetic Resonance (NMR) spectra were recorded for CHT-g-PEI and CHTg-PEI-PEG- $\mathrm{NH}_{2}$ conjugates. Proton NMR chemical shifts, expressed in ppm and analyzed in deuterated water $\left(\mathrm{D}_{2} \mathrm{O}\right)$ doped with deuterated acetic acid $\left(\mathrm{CD}_{3} \mathrm{COOD}\right)$ in a ratio of $5: 1$ were recorded on a $500 \mathrm{MHz}$ Avance III spectrometer (Bruker BioSpin $\mathrm{GmbH}$, Germany) at room temperature.

2.5. Particle Size, Surface Charge, Conductivity, and Structural Morphology Measurement. Malvern Zetasizer Nano ZS (Malvern Instruments, Worcestershire, UK) was employed to evaluate the size, zeta potential, and the conductivity of the nanoparticles. Known sample weights were dispersed in DDW and sonicated for 30 seconds. $2 \mathrm{~mL}$ dispersed sample $(2 \mathrm{~mL})$ was placed in disposable cuvettes and the dynamic scatter intensity was recorded at $25^{\circ} \mathrm{C}$. The average zeta size, polydispersity index (PDI), zeta potential, and conductivity of the nanoparticles were recorded.

The size of the nanoparticles was also confirmed using Transmission Electron Microscopy (TEM) (FEI Tecnai T12 TEM, 60-120 kV, Hillsboro, OR, USA). The nanoparticle system was dispersed in DDW, ultrasonicated for 15 minutes and a single drop of the nanoparticle suspension was dropped on a Form $\operatorname{Var}^{\circledR}$ coated 200-mesh copper grip (TAAB Laboratories Equipment Ltd., Aldermaston, England) and allowed to air dry at $25^{\circ} \mathrm{C}$ prior to TEM analyses.

The morphology of the nanoparticles was examined using Scanning Electron Microscopy (SEM). Powdered sample of the nanoparticles was placed onto an aluminium specimen stubcovered with a double-sided carbon adhesive disc and sputter-coated with both palladium and gold for 4 minutes at $20 \mathrm{kV}$. SEM images of endostatin-loaded nanoparticles were then viewed by a Scanning Electron Microscope (SIGMA VP, ZEISS Electron Microscopy, Carl Zeiss Microscopy Ltd.; Cambridge, UK).

2.6. Determination of the Drug-Loading Capacity and Entrapment Efficiency of the Nanoparticles. Known amounts ( $3 \mathrm{mg}$ ) of drug-loaded nanoparticles of the 15 formulations and the optimized nanosystems was dispersed in $5 \mathrm{~mL}$ DDW and shaken vigorously. The mixture was then centrifuged for 1 hour at $5000 \mathrm{rpm}$. The clear supernatant solution $(2 \mathrm{~mL})$ was poured into the UV cuvette and the absorbance of the drug was read at $280 \mathrm{~nm}$ for all samples using a NanoPhotometer. Measurements were performed in triplicate andthe corresponding drug concentrations were computed from a standard calibration curve. The drug-loading capacity (LC) and entrapment efficiency (EE) of the nanoparticles were calculated using (1) and (2), respectively: 


$$
\begin{aligned}
& \mathrm{LC}=\frac{\text { Total amount of drug loaded }- \text { Unloaded drug in the supernatant }}{\text { Measure weight of drug loaded nanoparticles }}, \\
& \mathrm{EE}=\frac{\text { Total amount of drug loaded }- \text { Unloaded drug in supernatant }}{\text { Total amount of drug loaded }}
\end{aligned}
$$

2.7. Determination of the Degree of Swelling of the Nanoparticles. The swelling behaviour of the synthesized nanoparticles was determined at both $\mathrm{pH} 6.8$ and 7.4 using the Malvern Zetasizer Nano ZS (Malvern Instruments, Worcestershire, UK). Known amounts of nanoparticles were incubated at $37^{\circ} \mathrm{C}$ in phosphate buffered saline (PBS, pH 6.8 and 7.4) over 4 hours. The average size of nanoparticles $(\mathrm{nm})$ was recorded at $0,1,2$, and 4 hours. Each sample was sonicated for 30 seconds (SONICS Vibra Cell ${ }^{\mathrm{TM}}$, Newtown, CT, USA), placed in disposable polystyrene cuvettes and the dynamic scatter intensity was recorded at $25^{\circ} \mathrm{C}$ for the corresponding $\mathrm{pH}$ at the specific time interval.

2.8. In Vitro Drug Release and Chromatographic Apparatus/Condition for Reverse Phase HPLC. The drug release experiments were carried out at $37^{\circ} \mathrm{C}$ in an orbital shaker incubator (YIHDER, Taiwan) over 16 hours. Equivalent amounts of the BSA-loaded and endostatin-loaded nanoparticles were placed in a $15 \mathrm{~mL}$ centrifuge tube with $5 \mathrm{~mL}$ PBS buffer at both tumoral $\mathrm{pH}$ of 6.8 and physiological $\mathrm{pH}$ of 7.4. The release buffer medium $(2 \mathrm{~mL}$ aliquot) was removed at predetermined time intervals $(1,2,4,6,8$, and 16 hours), filtered, and replaced with fresh amount of the buffer medium to maintain sink conditions. UV absorbance of the filtered samples was then measured at $280 \mathrm{~nm}$ using the Alliance HPLC system, including Waters 2695 Separations module Waters 996 PDA Detector; Millennium 32 chromatography analysis software, Waters Symmetry $300^{\mathrm{TM}} \mathrm{C} 18$ $(4.6 \mathrm{~mm} \times 250 \mathrm{~mm}, 5 \mu \mathrm{m})$, Waters 1525 binary pump, and Waters 2489 UV/visible detector, Superdex ${ }^{\text {TM }}$ 75Nhr 10/30 column. The fixed phase is Symmetry 300TM C18 $(4.6 \mathrm{~mm}$ $\times 250 \mathrm{~mm}, 5 \mu \mathrm{m})$. Mobile phases, solution A is $0.1 \%$ TCAwater $(1: 1000)$, solution B is $0.1 \%$ TCA-95\% CAN $(1: 1000)$; flow rate is $1.0 \mathrm{~mL} / \mathrm{min}$. The temperature of the column or sample plate was set at $30^{\circ} \mathrm{C}$ and samples were quantified by the Lowry method. The cumulative BSA or endostatin release was measured as a function of time.

2.9. Optimization of the Formulatory Components Using BoxBehnken Experimental Design. Polynomial equations relating the dependent and independent variables using Minitab Statistical Software $\left(\right.$ MINITAB $^{\circledR}, \mathrm{V} 15$, Minitab, USA) were employed to calculate the optimized delivery system from the formulation process under constrained conditions for the measured responses. Using the optimization parameters, optimized endostatin-loaded nanoparticles were prepared following the same method employed for the 15 formulations. However, $0.5 \mathrm{mg} / \mathrm{mL}$ human recombinant endostatin was loaded into the nanoparticles. For generation of the optimum formulation, the average nanoparticle size as well as the in vitro cumulative endostatin release from the loaded nanoparticles at $\mathrm{pH} 7.4$ was minimized, while the release at tumor $\mathrm{pH}$ of 6.8 and the overall average surface charge of the nanoparticles was maximized. Response analysis was performed for all the variables tested. Surface and contour plots derived from the responses were used to authenticate the effects of the independent variables on the response factors.

\subsection{Nanoparticle Cytocompatibility and Cell Proliferation} Assay. In vitro cell cytotoxicity was determined using Alamar blue assay. Human oesophageal squamous cell carcinoma cell line (KYSE-30) (Life Bioscience) were seeded in complete media comprising RPMI and Ham's F12 (1:1), supplemented with $10 \%$ Fetal Bovine Serum, $2 \mathrm{mM}$ glutamine, sodium bicarbonate, and $100 \mu \mathrm{L}$ penicillin/streptomycin (Sigma-Aldrich; St. Louise, MO, USA). The cells were maintained in an incubator (RS Biotech Galaxy, Irvine, UK), with a humidified atmosphere of $5 \% \mathrm{CO}_{2}$ at $37^{\circ} \mathrm{C}$. KYSE30 cells were diluted in a complete medium at a final concentration of $5 \times 10^{4}$ cells $/ \mathrm{mL}$ and seeded $(25 \mu \mathrm{L} /$ well $)$ and incubated for 24 hours prior to cell proliferation evaluation using Alamar blue assay according to the manufacturer's procedures. Native nanoparticles and endostatinloaded nanoparticles were dissolved in the serum-free culture medium at varying concentrations of endostatin $(125 \mu \mathrm{g} / \mathrm{mL}$, $250 \mu \mathrm{g} / \mathrm{mL}, 500 \mu \mathrm{g} / \mathrm{mL}$ and $1000 \mu \mathrm{g} / \mathrm{mL}$ ). Attached cells in the wells were treated with the various nanoformulations in triplicate for 24 hours and cell viability was quantified at maximum emission/excitation wavelengths of $535 \mathrm{~nm}$ and $595 \mathrm{~nm}$, respectively, on a microplate reader (FilterMax ${ }^{\mathrm{TM}} \mathrm{F} 5$ Multi-Mode Microplate Reader, Molecular Devices, USA). Attached cells treated only with serum-free media, without the nanoformulation, were used as a control. Results are presented as percentage cell viability ( $\% \mathrm{CV} \pm$ mean standard deviation), with the percentage of viable cells was calculated using the following Equation (3).

$$
\begin{aligned}
& \mathrm{CV} \\
& \text { Fluorescence reading in treated cells } \\
& =\overline{\text { Fluorescence reading in control (untreated) cells }} \text {. }
\end{aligned}
$$

\section{Results and Discussion}

3.1. Polymer Grafting and Nanoparticle Synthesis and Characterization. As presented in the reaction schematics in Figure 1, the amine in acetylated low molecular weight CHT was grafted to the amine of $25 \mathrm{KDa}$ branch PEI through the CDI linkage chemistry. The two imidazolyl groups of CDI 


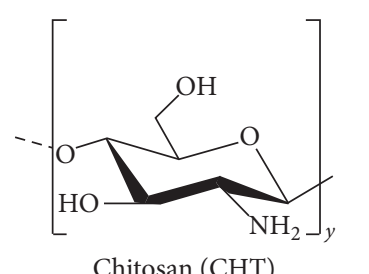

Chitosan (CHT)<smiles>CC(C)(N)NCCN(CCN)CCNCCNCCN</smiles>

Branched PEI

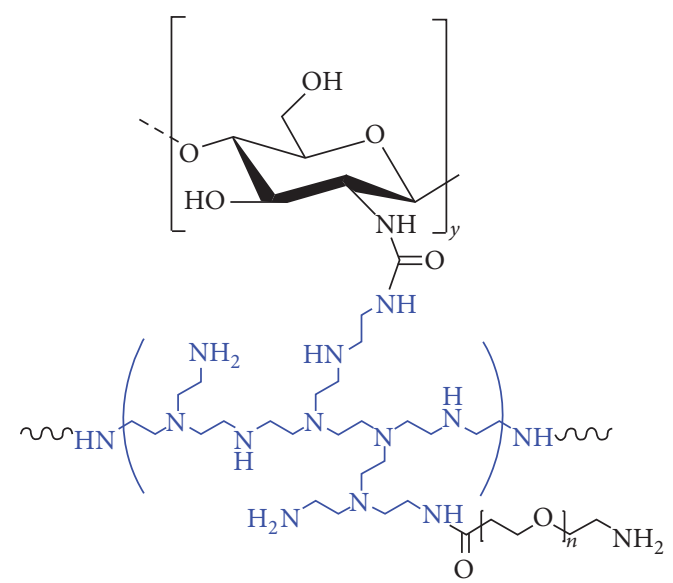

CHT-g-PEI-PEG-NH ${ }_{2}$

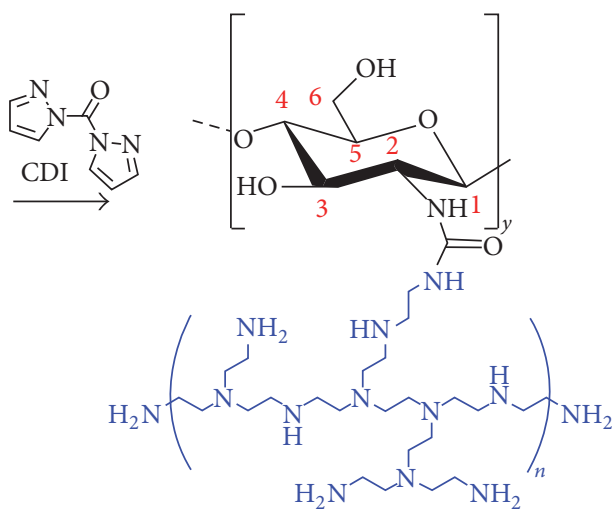

CHT-g-PEI

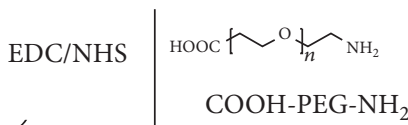

FIgURE 1: Proposed reaction scheme for the preparation of grafted polymers.

were used to couple the amines of both CHT and PEI. The feed molar ratio of PEI to amine of chitosan was $3: 1$ (based on our preliminary study). Similarly, amidation reaction between the carboxyl group on the bifunctional PEG and the free amine on the grafted CHT-g-PEI through NHS/EDC cross linkers was employed to synthesize the amino terminal CHT-PEI-PEG conjugate for endostatin encapsulation. The structural and functional modification of both CHT-g-PEI and CHT-g-PEI-PEG-NH $\mathrm{N}_{2}$ conjugates were confirmed by both ${ }^{1} \mathrm{H}$ NMR and FT-IR spectra as presented in Figures 2 and 3, respectively [19-24].

Figures 2(a) and 2(b) show the ${ }^{1} \mathrm{H}$ NMR spectra of the grafted copolymers and PEG functionalized grafted polymer conjugate, respectively. From Figure 2(a), characteristic peaks at $\delta=2.9-3.7 \mathrm{ppm}$ were assigned to $\mathrm{D}$-glucosamine unit $(\mathrm{H} 3, \mathrm{H} 4, \mathrm{H} 5$, and $\mathrm{H} 6)$ of $\mathrm{CHT}$, the peak at $\delta=3.1 \mathrm{ppm}$ is responsible for $\mathrm{H} 2$, and the peak at $\delta=1.9 \mathrm{ppm}$ is indicative of the methyl protons of $\mathrm{N}$-acetyl group. The presence of peaks at $\delta=2.5-3.2 \mathrm{ppm}$ was assigned to methylene protons of PEI $\left(-\mathrm{NHCH}_{2} \mathrm{CH}_{2}-\right)$ and confirmed that PEI was successfully grafted onto the $\mathrm{CHT}$ chain. Similar results were reported by Sarkar and coworkers [19] for the preparation of fluorescent chitosan-graft-polyethyleneimine and Lui and coworkers [20] for chitosan-Graft-polyethylenimine/DNA nanoparticles. After the reaction between CHT-g-PEI and $\mathrm{COOH}-\mathrm{PEG}-\mathrm{NH}_{2}$, there were new peaks in the ${ }^{1} \mathrm{H}$ spectrum at $\delta=3.6 \mathrm{ppm}$ which belonged to the methylene protons of PEG $\left(-\mathrm{OCH}_{2} \mathrm{CH}_{2}-\right)$ (relative to Figure 2(a)). There was a slight downfield shift of the signals of the characteristic protons of CHT and PEI (Figure 2(b)). This is possibly due to the deshielding of protons (CHT and PEI) as a result of addition of $-\mathrm{OCH}_{2}$ of PEG moieties. Zhou et al. [24] reported similar downfield shifts for the methylene proton signals of PEI after conjugation to PEG monomethyl ether with a carboxyl end group (mPEG-COOH).

By comparing the integration of proton signals at $\delta=$ $2.5-3.2 \mathrm{ppm}$ and $\delta=2.9-3.7 \mathrm{ppm}$, the degree of substitution of PEI per CHT D-glucosamine unit was calculated (see (4)). The integration value of $\mathrm{H}-2$ was defined as 1 during the process of calculation.

$$
\begin{aligned}
& \text { Degree of substitution (DS) }=\frac{\left[I_{\mathrm{PEI}, \mathrm{CH}_{2} \mathrm{CH}_{2} \mathrm{NH}}\right] / 4}{\left[I_{\mathrm{CHT}, \mathrm{H} 2, \mathrm{H} 3-\mathrm{H} 6}\right] / 6} \\
& \quad=\frac{3.56 / 4}{5.51 / 6}=0.9
\end{aligned}
$$

Thereafter degree of grafted (DG) PEI onto CS was calculated via

$$
\mathrm{DG}=\frac{W_{2}}{W_{1}} \times 100 \%,
$$




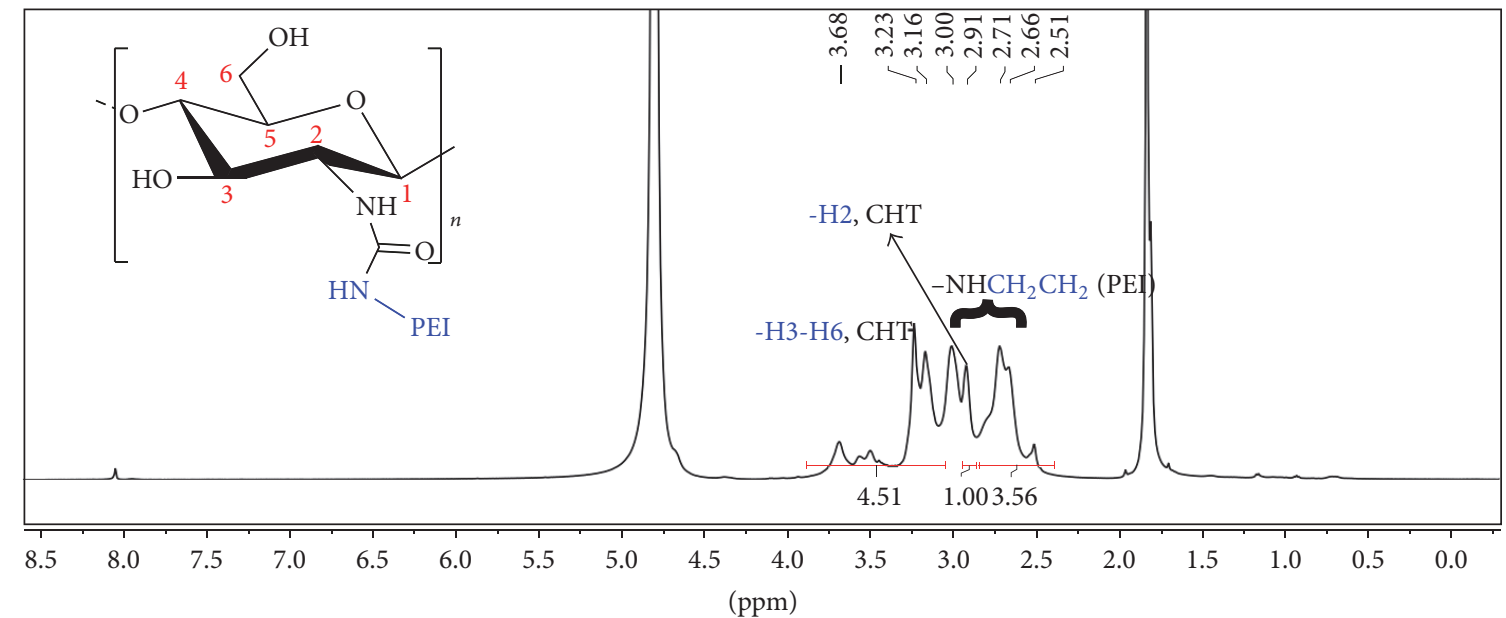

(a)

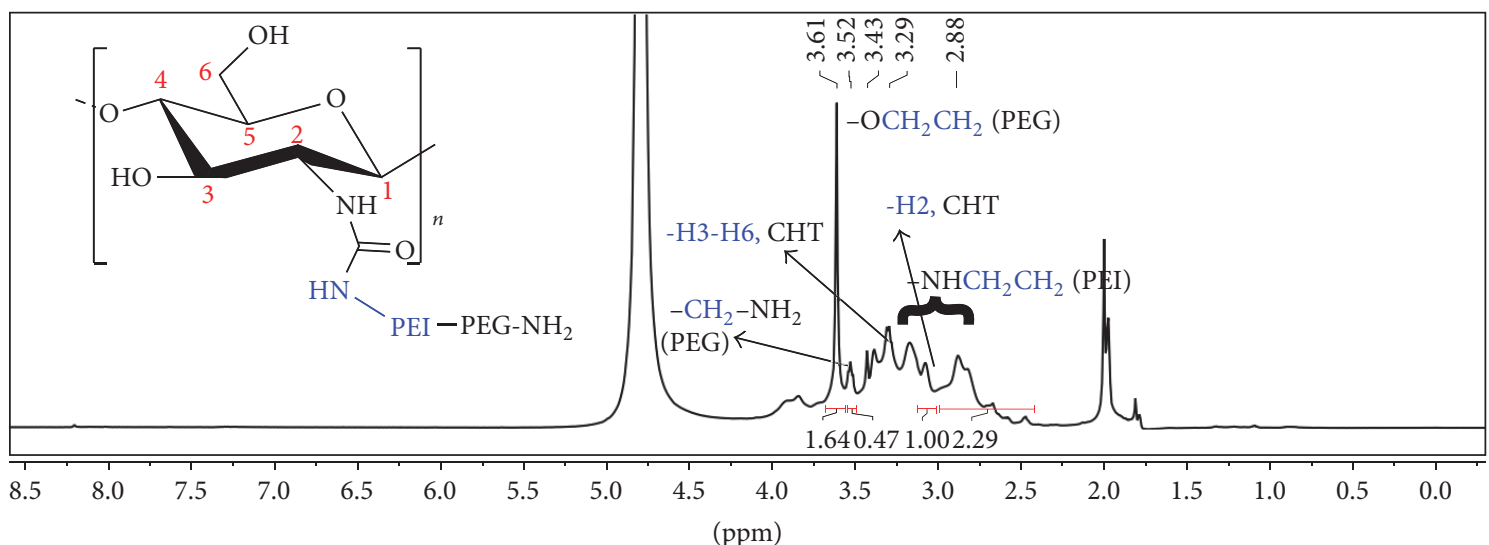

(b)

FIgURE 2: ${ }^{1} \mathrm{H}$ NMR spectra showing the grafting of polymer conjugates in $\mathrm{D}_{2} \mathrm{O}: \mathrm{CD}_{3} \mathrm{COOD}(5: 1)$. (a) CHT-g-PEI and and (b) CHT-g-PEIPEG-NH ${ }_{2}$.

where $W_{1}$ is mass of pure graft copolymer and $W_{2}$ is mass of graft chains

$$
\begin{aligned}
\mathrm{DG} & =\frac{24.25}{214.3} \mathrm{kDa} \times 100 \%=11.3 \% \\
W_{1} & =\mathrm{MW}_{\mathrm{CHT}}+\left(\mathrm{MW}_{\mathrm{PEI}} \times \mathrm{DS}\right) \\
& =190 \mathrm{kDa}+(25 \mathrm{kDa} \times 0.97)=214.3 \mathrm{kDa} \\
W_{2} & =n\left(\mathrm{MW}_{\mathrm{PEI}} \times \mathrm{DS}\right)=(25 \mathrm{kDa} \times 0.97) \\
& =24.25 \mathrm{kDa} .
\end{aligned}
$$

FT-IR spectra of the native and grafted polymers of CHT-gPEI-PEG-NH $\mathrm{N}_{2}$ grafted copolymer are presented in Figure 3. The absorption of $v(\mathrm{O}-\mathrm{H})$ and $v(\mathrm{~N}-\mathrm{H})$ at $3450-3200 \mathrm{~cm}^{-1}$, $\nu(\mathrm{C}-\mathrm{H})$ at $\sim 2930$ and $2886 \mathrm{~cm}^{-1}, \nu\left(\mathrm{C}=\mathrm{O} \mathrm{NH}_{2}\right)$ at 1656 and $1597 \mathrm{~cm}^{-1}$, and $\nu(\mathrm{C}-\mathrm{O}-\mathrm{C})$ at $1150 \mathrm{~cm}^{-1}$ in the FT-IR spectra was assigned to CS D-glucosamine units thereby indicating the presence of chitosan as the core polymer framework in the synthesized CHT-g-PEI-PEG- $\mathrm{NH}_{2}$ conjugate (Figure 3(e)). A new peak appeared at $\sim 1590 \mathrm{~cm}^{-1}$, which is indicative of the carboxyl in urea group (Figure 3(c)). Further, the appearance of peaks at 1450.6 and $822.1 \mathrm{~cm}^{-1}$ was attributed to the absorption of $-\mathrm{NHCH}_{2} \mathrm{CH}_{2}$ - moieties which is from the branched PEI, indicating that PEI was successfully grafted onto CHT [22].

The formation of an amide bond between the carboxylic group of PEG and the amine group of CHT-g-PEI copolymer was noted in the CHT-g-PEI-PEG- $\mathrm{NH}_{2}$ conjugate. As represented in the FT-IR spectrum in Figure 3(e), the characteristics peak at $1696.5 \mathrm{~cm}^{-1}$ was assigned to the absorption from the $\mathrm{C}=\mathrm{O}$ stretch in amide bond I, 1463.7 and $1496.4 \mathrm{~cm}^{-1}$ were peaks attributed to the absorptions from both the N-H bend and C-N stretch in amine bond II while the tripartite absorption peaks at $1310.0,1279.6$, and $1251.9 \mathrm{~cm}^{-1}$ were attributed to the N-H bend in plane and C-N stretch in amide bond III. Meanwhile, an absorption peak at $3389.4 \mathrm{~cm}^{-1}$ was attributed to the $\mathrm{N}-\mathrm{H}$ stretch from the free primary amine group attached to the PEG in the conjugate (CHT-g-PEIPEG-NH$H_{2}$ ). Similarly, the characteristic peak of PEI was represented as an absorption peak of $822.1 \mathrm{~cm}^{-1}$ while the peak at $871.2 \mathrm{~cm}^{-1}$ was assigned to CHT [23]. Notably, the 


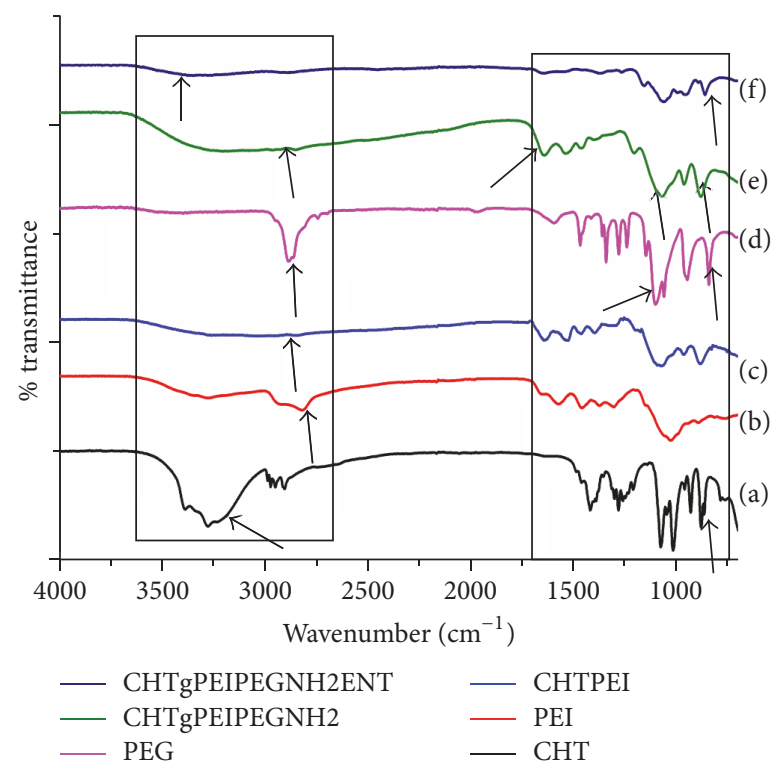

FIGURE 3: FT-IR spectra for native polymers, grafted polymer conjugates, and the endostatin-loaded nanoparticle system.

characteristic peak of PEG at $842 \mathrm{~cm}^{-1}$ contributing to the absorption of $\mathrm{CH}_{2}$ from $-\left[\mathrm{CH}_{2} \mathrm{CH}_{2} \mathrm{O}\right]_{n}$ - was also found in the spectrum of the CHT-g-PEI-PEG- $\mathrm{NH}_{2}$ polymer conjugate, which confirms its presence in the polymer construct [24].

The degree of grafting (DG) of PEG onto CS-g-PEI was calculated based on the ${ }^{1} \mathrm{H}$ NMR using the integration of proton signals:

$$
\begin{aligned}
\mathrm{DS}_{\mathrm{PEG}} & =\frac{\left[\mathrm{I}_{\mathrm{PEG}, \mathrm{CH}_{2} \mathrm{NH}_{2}}\right] / 2}{\left[I_{\mathrm{CHT}-\text { g-PEI-PEG,CH}} \mathrm{CH}_{2} \mathrm{NH}_{2}\right] / 4}=\frac{0.47 / 2}{2.29 / 4} \\
& =0.41 \\
\mathrm{DG} & =\frac{0.861}{215.2} \mathrm{kDa} \times 100 \%=0.40 \% \\
W_{1} & =\mathrm{MW} \mathrm{CHT}-\mathrm{g}-\mathrm{PEI}+\left(\mathrm{MW}_{\mathrm{PEG}} \times 0.41\right) \\
& =214.3 \mathrm{kDa}+(2.1 \mathrm{kDa} \times 0.41)=215.29 \mathrm{kDa} \\
W_{2} & =n\left(\mathrm{MW}_{\mathrm{PEG}} \times \mathrm{DS}\right)=(2.1 \times 0.41)=0.86 \mathrm{kDa} .
\end{aligned}
$$

3.2. Confirmation of the Physicochemical Properties and Morphology of Endostatin-Loaded Nanoparticles. Physicochemical properties, such as average particle size, surface zeta potential, conductivity, and polydispersity index (PDI), of BSA/endostatin-loaded nanoparticles were measured using Dynamic Light Scattering (Zetasizer NanoZS, Melvern Instrument, UK). Table 1 shows the average particle size for the 15 formulations as influenced by the formulation variables. The average size of the nanoparticles ranged between $56.28 \mathrm{~nm}$ (F11) and $363.10 \mathrm{~nm}$ for F14. Although formulations with similar concentration of the grafted polymer conjugates (CHT-g-PEI-PEG) seemed to have closely related average particle size ( $\mathrm{F} 2=84.22 \mathrm{~nm}$ and $\mathrm{F} 4=97.38 \mathrm{~nm})$, the surfactant concentration seemed to be a major determining factor for the average particle size distribution among the 15 formulations generated using the Box-Behnken design. For instance, the average particle sizes for F5, F6, and F15 with a polymer conjugate concentration $(1.5 \mathrm{mg} / \mathrm{mL})$ were 300.10 , 295.10, and $310.20 \mathrm{~nm}$, respectively, while F1 and F4 with the same polymer conjugate concentration $(1.5 \mathrm{mg} / \mathrm{mL})$ had average particle sizes of 56.28 and $97.38 \mathrm{~nm}$, respectively, at a ratio of approximately $1: 3$, in comparison to F5, F6, and F15. Both F1 and F4 had a surfactant concentration of 1\% PVA solution while F5, F6, and F15 had surfactant concentration of $0.55 \%$ PVA. Meanwhile, the concentration of TPP, as a polyionic agent, for the nanoparticle synthesis also influenced the average particle size of the nanoparticles among the 15 formulations. Formulations with the lowest TPP concentrations (F1 and F2) (0.1\% TPP) had the lowest average particle size $(\mathrm{F} 1=65.07 \mathrm{~nm}, \mathrm{~F} 2=84.22 \mathrm{~nm})$ compared to F14 $=363.10 \mathrm{~nm}, 0.3 \% \mathrm{TPP}$ as shown in Table 1 . This is because crosslinking agents, such as TPP, harden the matrix of chitosan nanoparticles leading to decreased water absorption [21]. However, higher PVA (1\%, 0.55\%, 0.55\%) and TPP concentrations $(0.3 \%)$, as seen in F4, F8, and F11, seemed to be favorable for the synthesis of moderately sized endostatinloaded nanoparticles ranging between $56.28 \mathrm{~nm}$ for F11 and $97.38 \mathrm{~nm}$ for F4. In general, increased concentrations of the polymer conjugate $(2.5 \mathrm{mg} / \mathrm{mL})$ and TPP $(0.3 \%)$ with reduced PVA concentration ( $0.55 \%$ ) lead to the synthesis of a reduced average particle size $(\mathrm{F} 11=56.28 \mathrm{~nm})$. This could be as a result of strong electrostatic interactions between the BSA/endostatin molecules and the increased positively charged amino groups of $\mathrm{CHT}$ at higher concentration, as the main component in the grafted polymer conjugate [25]. Furthermore, increased electrostatic interaction between the negative charge of TPP as a polyanionic agent at higher concentration and the positively charged amino group of $\mathrm{CHT}$ could possibly account for the reduction in nanoparticle size [25]. Thus, the optimized endostatin-loaded nanoparticles were prepared at CHT concentration of $2.5 \mathrm{mg} / \mathrm{mL}$ and have an average hydrodynamic size of $100.6 \mathrm{~nm}$ (Figure 4). The PDI value of the nanoparticles from the 15 formulations ranged between 0.259 and 1.00. Interestingly, nanoparticles from most of the formulations had PDI value less than 1.00 showing their uniform disparity in solution. More importantly, the optimized nanoparticles have a PDI of 0.274 .

The zeta potential values were positive for most of the formulations (Table 1). Overall, formulations with reduced chitosan concentration in the grafted polymer conjugate $(0.5 \mathrm{mg} / \mathrm{mL})$ tend to have reduced zeta potential. The zeta potential decreased from a more positive charge towards negative charge surfaces as the polymer conjugate concentration decreased from 2.5 to $0.5 \mathrm{mg} / \mathrm{mL}$ (F3, F7, and F11 compared to F9, F12, and F13). Meanwhile, as the concentration of TPP, as the polyanionic agent decreased in the formulations, the PDI values increase across the formulations towards more positively charged surfaces with increasing chitosan concentration in the grafted polymer conjugate $(\mathrm{F} 7=+11.00$ compared with $\mathrm{F} 10=+0.76$; and $\mathrm{F} 1=+16.10$ and $\mathrm{F} 2=$ +19.80 , compared with F4 $=-1.87$ and F14 $=-7.63$ ). It is 


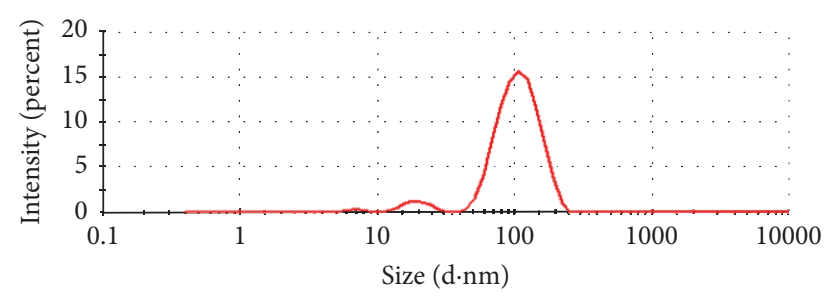

(a)

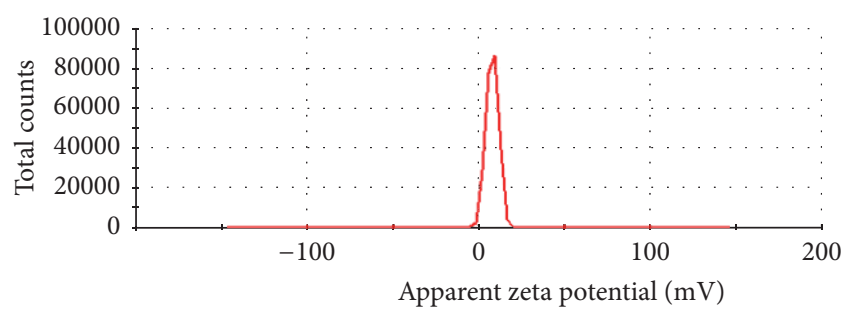

(b)

Figure 4: Hydrodynamic size and surface charge of optimized endostatin-loaded nanoparticle. (a) Average nanoparticle size is $100.6 \mathrm{~nm}$ with PDI value of 0.274 and (b) surface zeta potential of nanoparticles is $+7.95 \mathrm{mV}$.

proposed that the overall positive charge on the surface of the nanoparticles originates from the protonation of the free amines on the chitosan component of the grafted polymer conjugate (CHT-g-PEI-PEG- $\mathrm{NH}_{2}$ ) as chitosan is the main polymer in the conjugate. Interactions between the negatively charged TPP solution and the positively charged chitosanbased polymer conjugate determined the overall surface charge of the synthesized nanoparticles. Thus, formulations with lower TPP concentration and higher concentration of the grafted polymer conjugate have more positively charged surfaces. Reports have shown that the surface of tumor cells is negatively charged [26-28]. Interestingly, the optimized endostatin-loaded nanoparticle has an average positive zeta potential value of $7.95 \mathrm{mV}$ (Figure 4) which predisposed it for direct targeting in squamous cell carcinoma, as later presented in this study [29].

Both TEM and SEM micrographs (Figures 5 and 6, resp.) confirmed the morphology of endostatin-loaded nanoparticles to be spherical with transparent surfaces. Nanoparticle shape and size have been reported to influence internal cellular binding and uptake of drug-loaded nanoparticles [30-32]. Importantly, spherical shape nanoparticles possess enhanced cellular binding and internalization compared to nanoparticles with other shape configurations [33]. The TEM images further confirmed that endostatin-loaded nanoparticles with an average size less than $100 \mathrm{~nm}$ were successfully synthesized in agreement with the DLS average size measurement. The SEM micrograph also suggested that some of the smaller particles possibly agglomerate to form larger nanoparticles [34] ranging between 200 and $400 \mathrm{~nm}$. However, it should be noted that SEM images of the nanoparticles are acquired in their dried solid state as opposed to TEM and DLS average size measurements where the nanoparticles were dispersed in liquid. Interestingly, the average size of the optimized

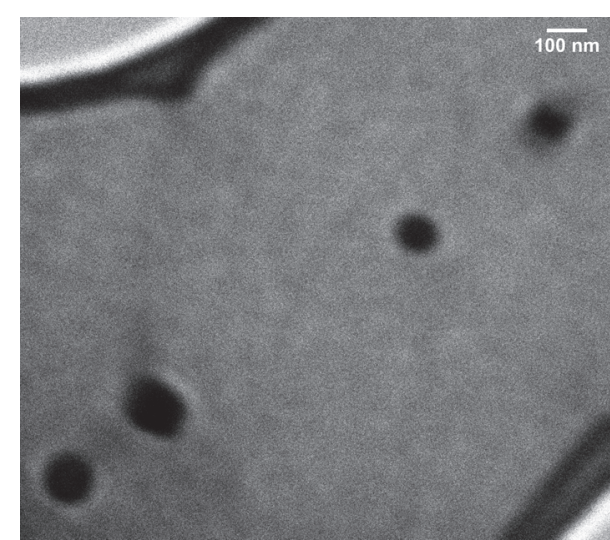

FIGURE 5: TEM images of optimized endostatin-loaded nanoparticles.

TABLE 2: Drug-loading capacity and entrapment efficiency.

\begin{tabular}{lcc}
\hline Formulations & Entrapment efficiency & Loading capacity (\%) \\
\hline F1 & 0.943 & 31.43 \\
F2 & 0.953 & 31.77 \\
F3 & 0.975 & 32.50 \\
F4 & 0.928 & 30.93 \\
F5 & 0.984 & 32.80 \\
F6 & 0.980 & 32.67 \\
F7 & 0.947 & 31.57 \\
F8 & 0.973 & 32.43 \\
F9 & 0.959 & 31.97 \\
F10 & 0.966 & 32.20 \\
F11 & 0.963 & 32.10 \\
F12 & 0.969 & 32.30 \\
F13 & 0.981 & 32.70 \\
F14 & 0.971 & 32.37 \\
F15 & 0.964 & 32.13 \\
\hline
\end{tabular}

endostatin-loaded nanoparticles are within the range for subcutaneous delivery intended for this study $[35,36]$.

\subsection{Confirmation of BSA/Endostatin Loading Capacity and} Entrapment Efficiency of Nanoparticles. As presented in Table 2, the drug-loading capacity and entrapment efficiency of the 15 formulations showed that BSA, as a model drug, was successfully loaded and entrapped within the grafted CHTbased polymeric network and ranged between 92.8\% (F4) and $98.4 \%$ (F5). This could be attributed to the influence of PEG coating on the surface of the nanoparticle. PEG coating has been found to increase encapsulation efficiency as free dissolved drugs are captured within the matrix of nanoparticles during PEGylation [21]. In general, formulations with lower CHT concentrations $(0.5 \mathrm{mg} / \mathrm{mL})$ showed higher loading and entrapment capacity (F8, F12, and F13 compared to F7, F10, and F11 with CHT concentration of $2.5 \mathrm{mg} / \mathrm{mL}$, Table 1). This could possibly be due to the lower viscosity that increases encapsulation of BSA or endostatin and possible promotion of gelation between CHT and TPP 


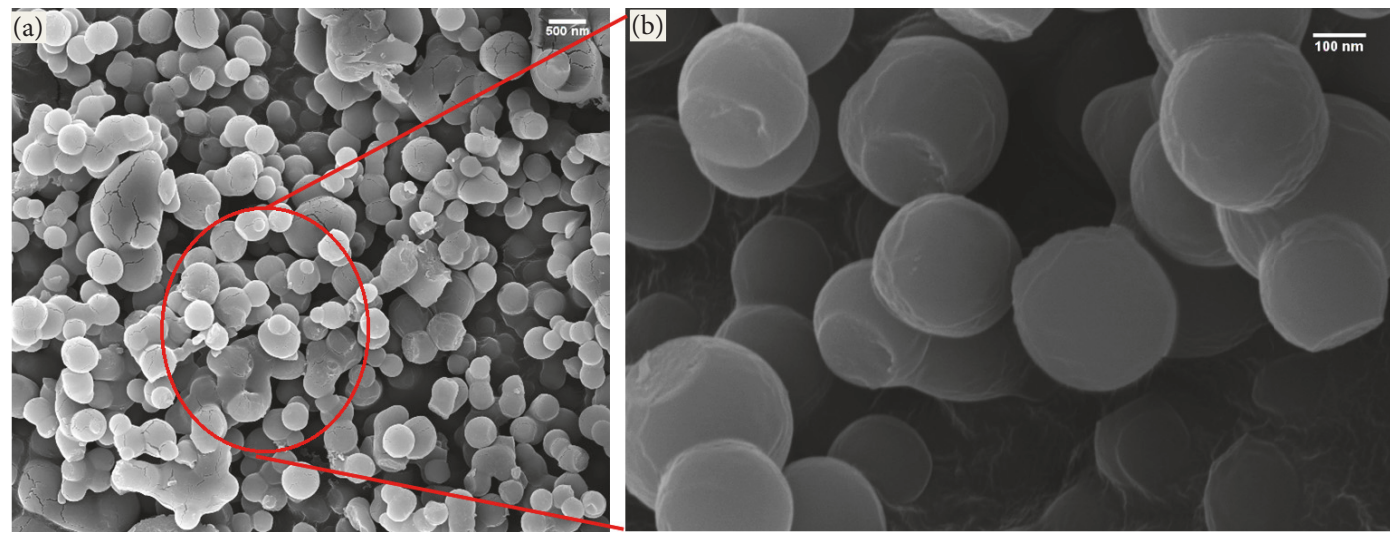

FIGURE 6: Gold-platinum sputtered SEM micrographs of the optimized ENT-loaded nanoparticles. (a) Magnification $=8.36 \mathrm{Kx}$. (b) Magnification $=50.00 \mathrm{Kx}$.

as the cross linking agent [21]. This corroborates the report of Vandenberg et al. [37] that the viscous nature of the gelation medium affects the drug encapsulation during the synthesis of chitosan microspheres. More so, effective confinement of BSA/endostatin molecules in the nanoparticles could be attributed to the electrostatic interaction between the proteins and the long chain of chitosan. Formulations F8, F11, and F14 with higher TPP concentrations $(0.3 \%)$ showed slightly higher encapsulation. This could be a result of increased crosslink density which possibly prevents the leaching away of entrapped BSA/endostatin molecules during formation of nanoparticles [21]. Further, high TPP concentration with a fixed chitosan concentration may increase the solution $\mathrm{pH}$ which consequently influences the overall negative charge at the surface of the BSA molecules. This enhances the electrostatic interactions between chitosan chains and BSA molecules and thus results in higher BSA loading and encapsulation efficiency.

3.4. Nanoparticle Swelling Behaviour and In Vitro Drug Release. As presented in Figure 7, the swelling capacity of BSA-loaded nanoparticles increased with time at the varying $\mathrm{CHT}$ concentrations. The degree of swelling was greater at $\mathrm{pH} 6.8$ than at $\mathrm{pH}$ 7.4, which would ultimately contribute to an enhanced release of the bioactivity at tumoral $\mathrm{pH}$. The effect of PEI and the surface shielding effect of PEG contributed to the swelling behaviour and BSA/endostatin release from the nanoparticles [21]. Overall, nanoparticle swelling reached equilibrium after 2 hours in the buffer system. RP-HPLC, as presented in Figure 8, was employed to quantitate the in vitro BSA/endostatin release from the BSA/endostatin-loaded nanoparticles as shown in Figure 11. BSA elute at 2.216 minutes over a run time of 6 minutes and result corroborates to previous report of Mukhopadhyay [38] and Mukhopadhyay et al. [39].

3.5. Effects of Chitosan and TPP Concentrations on Swelling and Release Kinetics. Chitosan concentration has been reported to play a major role in determining the swelling capacity and drug release kinetics of CHT-based nanoparticles [12]. Formulations with higher CHT concentrations showed a higher swelling ratio with increased BSA release from the nanoparticles. Furthermore, the concentration of the cross linker (TPP) has also been reported to influence the swelling behaviour of CHT-based nanoparticles [21]. Lower TPP concentrations allow for weak electrostatic interaction with the protonated amines of $\mathrm{CHT}$ and thus facilitate mass movement of the buffer solution into the matrix of the nanoparticles. At acidic $\mathrm{pH}$ (6.8 as presented in this study), the mass ratio of available protonated amino groups of $\mathrm{CHT}$ which can interact with TPP anions increased at a constant or lower TPP concentration (Figure 7(a)). This in turn results in a more loosely packed nanoparticle matrix which can be easily hydrated by the buffer solution and facilitate the release of the entrapped BSA/endostatin into the system. For instance, F10 has the highest cumulative BSA release at both $\mathrm{pH} 6.8(66 \%)$ and $\mathrm{pH} 7.4(58 \%)$ at CHT concentration of $2.5 \mathrm{mg} / \mathrm{mL}$ and TPP concentration of $0.2 \%$, compared to F8 having cumulative BSA release of $48 \%$ at $\mathrm{pH} 6.8$ and $40 \%$ BSA release at $\mathrm{pH} 7.4$ at CHT/TPP concentrations of $0.5 \mathrm{mg} / \mathrm{mL}$ and $0.3 \%$, respectively (Figure 9 ).

\subsection{Effects of pH on Nanoparticle Swelling and BSA/Endostatin} Release. The tumor microenvironment, including squamous cell carcinoma, and normal cellular physiological condition were both mimicked at $\mathrm{pH} 6.8$ and 7.4, respectively [40], to investigate the swelling behaviour and in vitro release kinetics of BSA-loaded nanoparticles. Overall, BSA release from within the nanoparticle matrix was increased at acidic $\mathrm{pH} 6.8$ compared to physiological $\mathrm{pH}$ of 7.4 across all formulations over a period of 16 hours (Figure 9(b)). Since $\mathrm{CHT}$ is the main component of the grafted polymer network forming the nanoparticles, the $\mathrm{pH}$-responsive characteristics of the BSA-loaded nanoparticles should be linked to the hydrolysis of $\mathrm{CHT}$ at changing $\mathrm{pH}$ conditions. The free amine groups in the CHT moiety within the polymer conjugate become protonated at acidic $\mathrm{pH}$, forming positively charged $\mathrm{NH}_{3}{ }^{+}$groups which are hydrophilic. This further results in an electrostatic repulsion among the protonated amino groups which weaken both the intra- and intermolecular hydrogen bonding interaction of CHT molecules. This in turn allows the enhanced permeation of the buffer solution 


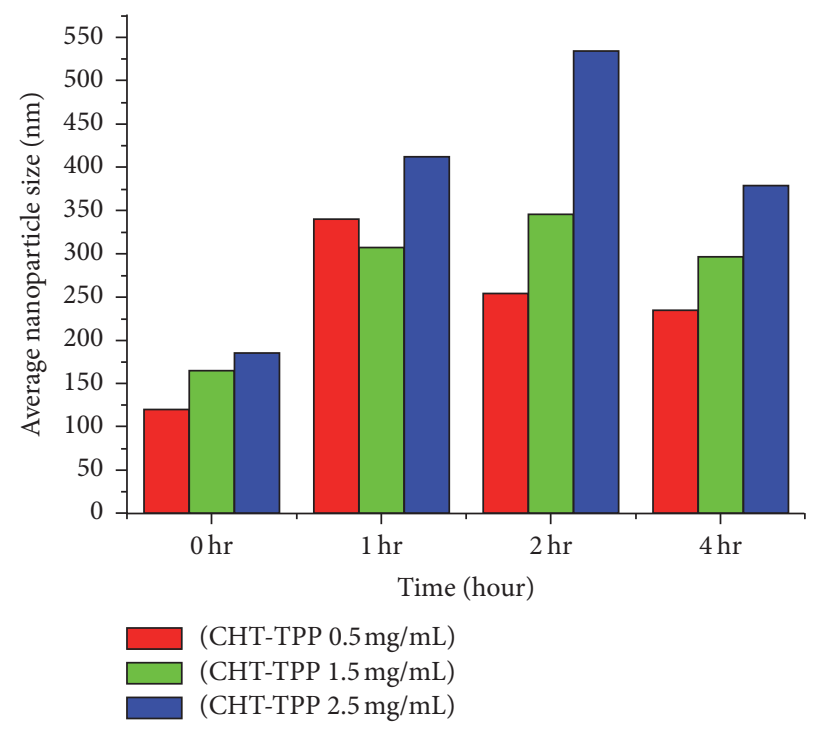

(a)

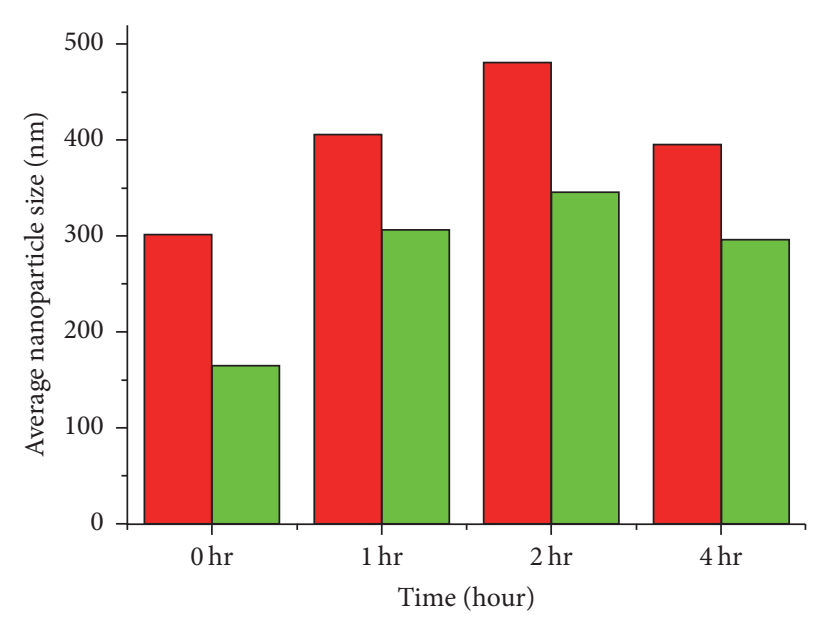

CHT-TPP (1.5 mg/mL)@pH6.8 CHT-TPP $(1.5 \mathrm{mg} / \mathrm{mL}) @ p H 7.4$

(b)

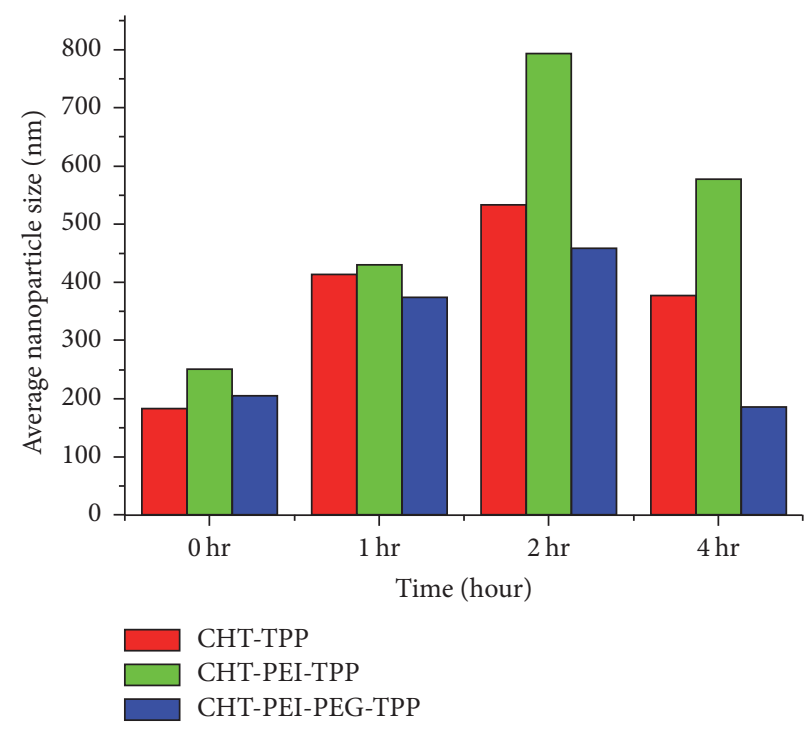

(c)

FIGURE 7: Swelling behaviour of drug-loaded nanoparticles. (a) Effect of varying CHT concentrations on swelling behaviour of nanoparticles. (b) Effect of varying $\mathrm{pH}$ conditions on the swelling behaviour nanoparticles at pH 6.8 and 7.4 resp. (c) Effect of PEI and PEG grafting on the swelling behaviour of nanoparticles.

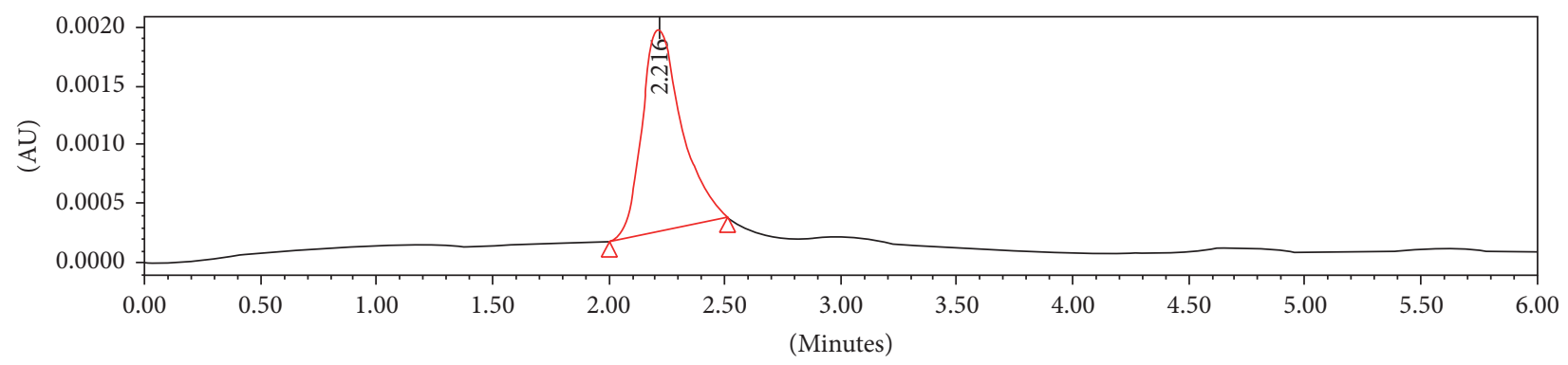

FIgURE 8: Reverse Phase HPLC chromatogram of BSA. Retention time of BSA as a model for endostatin is 2.216 minutes and run time is 6 minutes. No interference was observed for RP-HPLC for blank sample. Elusion was monitored at wavelength of $280 \mathrm{~nm}$ to detect BSA as previously reported [38]. 

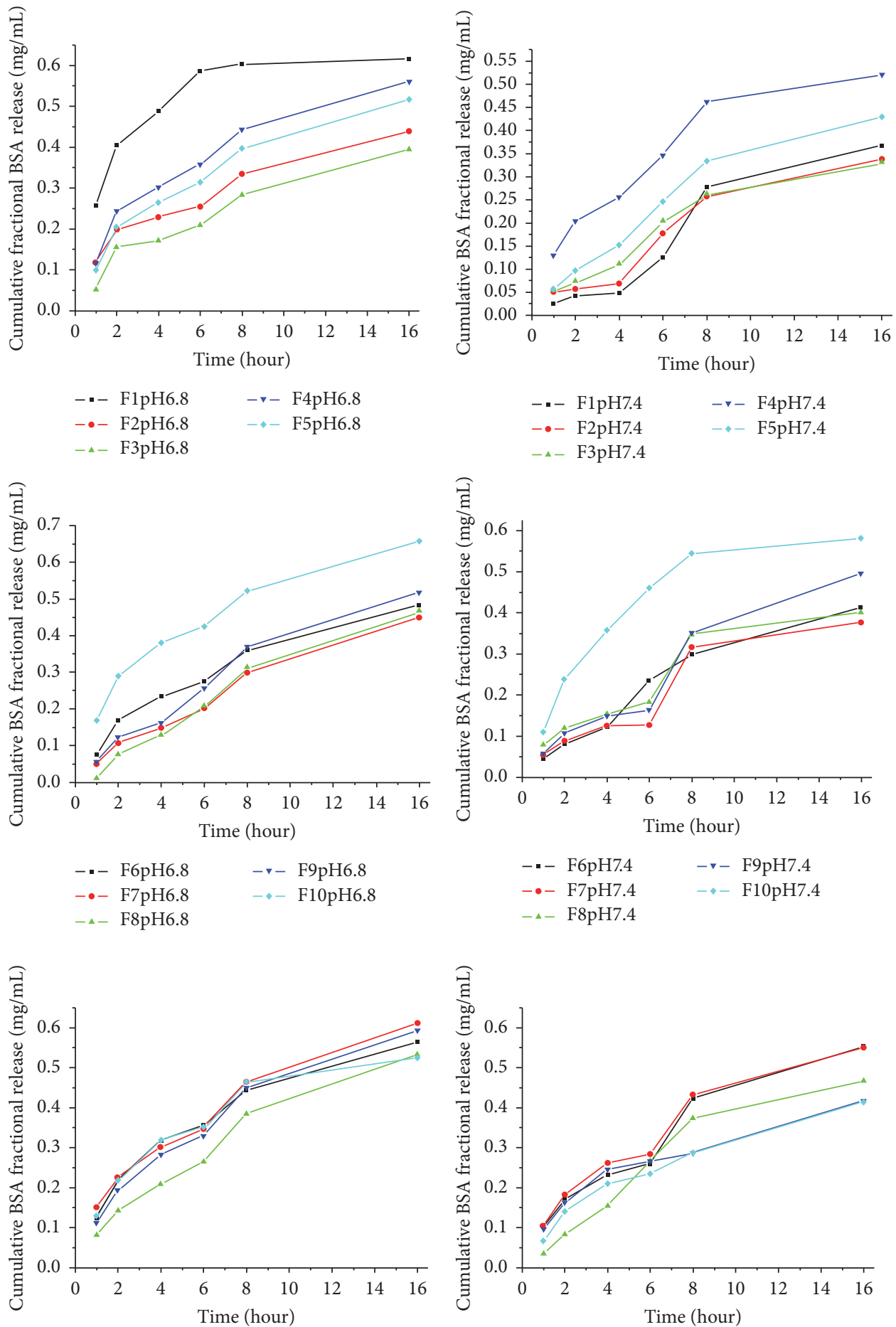

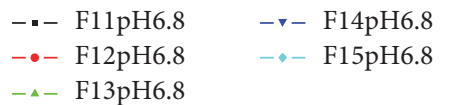

(a)

$$
\begin{array}{lll}
-\bullet-\text { F11pH7.4 } & \text { - }- \text { F14pH7.4 } \\
\text {-•- F12pH7.4 } & \text { - - F15pH7.4 } \\
\text {-^- F13pH7.4 } &
\end{array}
$$

(b)

Figure 9: Cumulative drug release of the 15 experimental design formulations at $\mathrm{pH} 6.8$ (a) and 7.4 (b). BSA release is higher at acidic pH of 6.8 than at physiological $\mathrm{pH}$ of 7.4 for each corresponding formulation. 
into the network therefore causing the equilibrium swelling ratio to increase as opposed to what is obtained at both neutral and basic $\mathrm{pH}$ conditions. In this study, swelling and shrinking mechanism with regard to swinging $\mathrm{pH}$ values has been investigated in terms of CHT-based smart responsive nanoparticulate systems for localized endostatin delivery.

3.7. Effects of PEI and PEGylation on Swelling and Drug Release. The protonating effects of the amines in PEI at low $\mathrm{pH}$ value contributed to the increased swelling of the nanoparticles as presented in Figure $7(\mathrm{c})$. At low $\mathrm{pH}$, the amino groups on both CHT and PEI become protonated and thereby increase the overall $\mathrm{NH}_{3}{ }^{+}$groups, which are hydrophilic. Thus, the buffering system could easily gain access into the nanoparticle network which facilitates an increase in the equilibrium swelling ratio. Meanwhile, the amphiphilic nature of PEG in the grafted polymer network possibly influenced the swelling property as well as the release pattern from the nanoparticles. PEGylation has increased the circulation time of PEG-modified nanosystems as well as prolonging the release of encapsulated drug in nanoparticulate systems [41-43]. In our system, the carboxyl group in the bifunctional PEG was used in grafting the amine group of PEI moiety in the CHT-based polymer conjugate. PEG is amphiphilic; its hydrophilic property depends on which part of the polymer is used during covalent reaction. The sheathing effect of PEG on the nanoparticle surface tends to increase the compact nature of the nanoparticulate system and, thus, reduce the swelling ratio of the drugloaded nanoparticle which in turn prolongs the release of the encapsulated drugs within the nanoparticle matrix. As evidenced in Figure 7(c), CHT-g-PEI-PEG nanoparticles have a reduced hydrated size as compared to both CHTPEI and CHT nanoparticle. At equilibrium swelling point after 2 hours, CHT-g-PEI-PEG-NH ${ }_{2}$ nanoparticles had an average size of $458.9 \mathrm{~nm}$, while both CHT-g-PEI and CHT nanoparticles had sizes of 794.2 and $534.2 \mathrm{~nm}$, respectively.

\subsection{Optimization of the Experimentally Derived Box-Behnken} Formulations. The results of the response optimization procedure (MINITAB, V15, Minitab, USA) showed a direct relationship between the fitted data and the observed response. The surface plot results (Figure 10) showed the effects of the polymer complex concentration, the surfactant concentration, and TPP concentration on the overall average size of nanoparticles and their surface charge as well as ENT release from the nanoparticle matrix at changing $\mathrm{pH}$ conditions of 6.8 and 7.4. Nanoparticle size and ENT release at the lower acidic $\mathrm{pH}$ of the tumor microenvironment were maximized while zeta surface potential and ENT release at physiological $\mathrm{pH}$ were minimized. These responses were chosen to achieve an optimum desirability in terms of the nanoparticulate system performance in cancer nanomedicines. The optimized levels of the independent variables, the corresponding predicted response, $y$, and both the individual and composite desirability values are presented in Figure 11. The optimized formulation variables were $1.22 \mathrm{mg} / \mathrm{mL}$ for the grafted polymer conjugate $(1.22 \mathrm{mg} / \mathrm{mL}$ CHT, $0.25 \%$ PEI, and $1 \mathrm{mg} / \mathrm{mL}$ functionalized PEG), $0.10 \%$ PVA, and $0.12 \%$
TPP for the synthesis of endostatin-loaded nanoparticles. Based on the statistical desirability function, it was found that the composite desirability of the formulation was 0.86 . The experimentally derived values for the nanoparticle size, surface zeta potential, and ENT in vitro release of the optimized formulation was in close agreement with the predicted values (size $=100.6 \mathrm{~nm}, P D I=0.274$, surface zeta potential $=7.95 \mathrm{mV}$, and $t_{8 \mathrm{~h}}=0.39$ ), demonstrating the reliability of the optimization procedure in predicting the unique behaviour of the desired nanoformulation having an average nanoparticulate size and surface charge for efficient cellular binding and uptake and internalization as well as having an improved, sustained, and efficient release pattern of ENT at tumor acidic microenvironment, as demonstrated in Figure 12.

3.9. Confirmation of Cytocompatibility and Antiangiogenic Effect of Endostatin-Loaded Nanoparticles. Cytotoxicity of endostatin-loaded and unloaded nanoparticles and their antiangiogenic effects on oesophageal squamous cell carcinoma (OSCC) were assessed by treating KYSE-30 cell line with varying concentrations of these nanoformulations. There is no significant difference in cell viability of the native polymer conjugate when compared to the control experiment (untreated cells) at polymer concentrations ranging between 125 and $500 \mu \mathrm{g} / \mathrm{mL}$ (Figure 13). Percentage cell viability was above $80 \%$. A major significant difference only occurred at a concentration of $1000 \mu \mathrm{g} / \mathrm{mL}$ of the polymer conjugate (63.85\% of native polymers conjugate treatment when compared to the control). Thus, this formulation has potential for use in the delivery of cancer therapeutics without toxicity concern since percentage cell viability of $80 \%$ or above shows good cytocompatibility of tested formulations [44, 45].

Although the polymers employed for nanoparticle synthesis were shown to have good cytocompatibility and to be not toxic, it is possible for nanoparticles to display specific toxicity because of their size and their accumulation and degradation in cells after internalization or due to the addition of other excipients during their preparation [46]. Our findings indicate that blank nanoparticles from the polymer will not affect the results from the proliferation assay performed with endostatin-loaded nanoparticles for the same treatment time. As such, oesophageal squamous cell carcinoma (KYSE-30) cells' proliferation was subsequently examined in response to endostatin-loaded nanoparticles.

Reports have shown that endostatin blocks endothelial cycle progression and reduces the expression of proliferation genes [47]. It induces endothelial cell proliferation [48] and apoptosis pathways in the $\mu \mathrm{g} / \mathrm{mL}$ range [49]. The antiangiogenic efficacy of endostatin-loaded nanoparticles has been well reported $[10,50,51]$. As presented in our study (Figure 13), endostatin-loaded nanoparticles showed a significant reduction in cell viability $(38.32 \%)$ over a concentration of $1000 \mu \mathrm{g} / \mathrm{mL}$. We observed $5.32 \%$ proliferation inhibition in response to nanoparticle concentration of $125 \mu \mathrm{g} / \mathrm{mL}$ over 24 hours' incubation period. Meanwhile, the proliferation inhibitory effect doubled to $13.36 \%$ at $250 \mu \mathrm{g} / \mathrm{mL}$ endostatinloaded nanoparticle concentration over the same treatment period. Interestingly, a dramatic increment in proliferation 

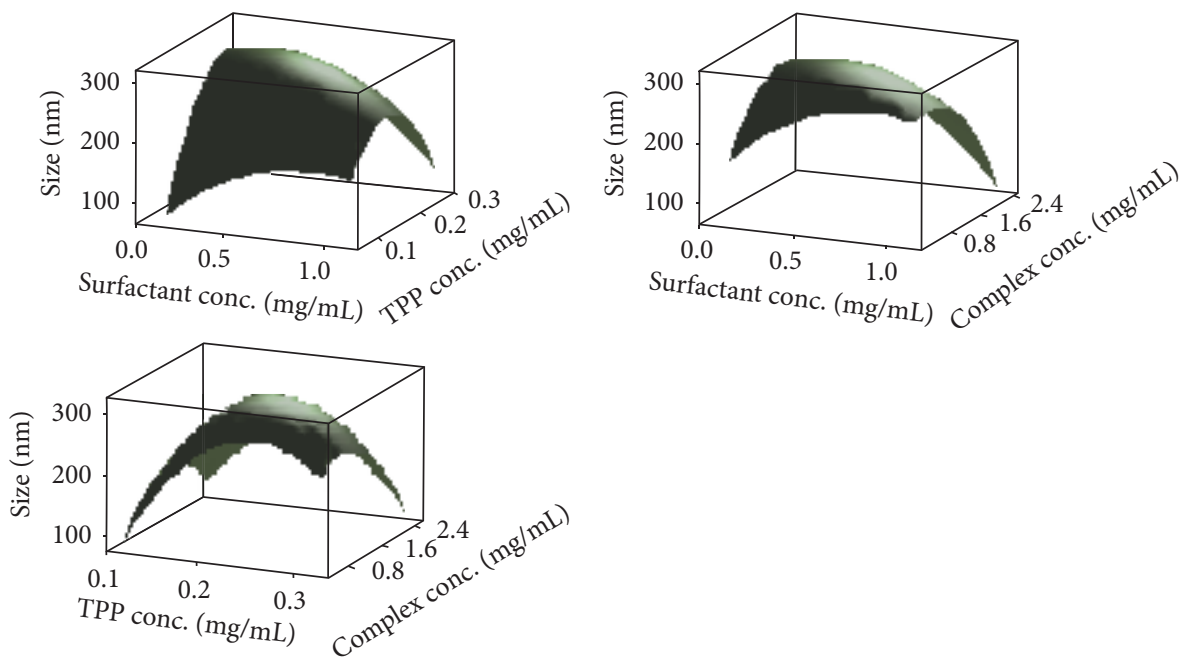

(a)
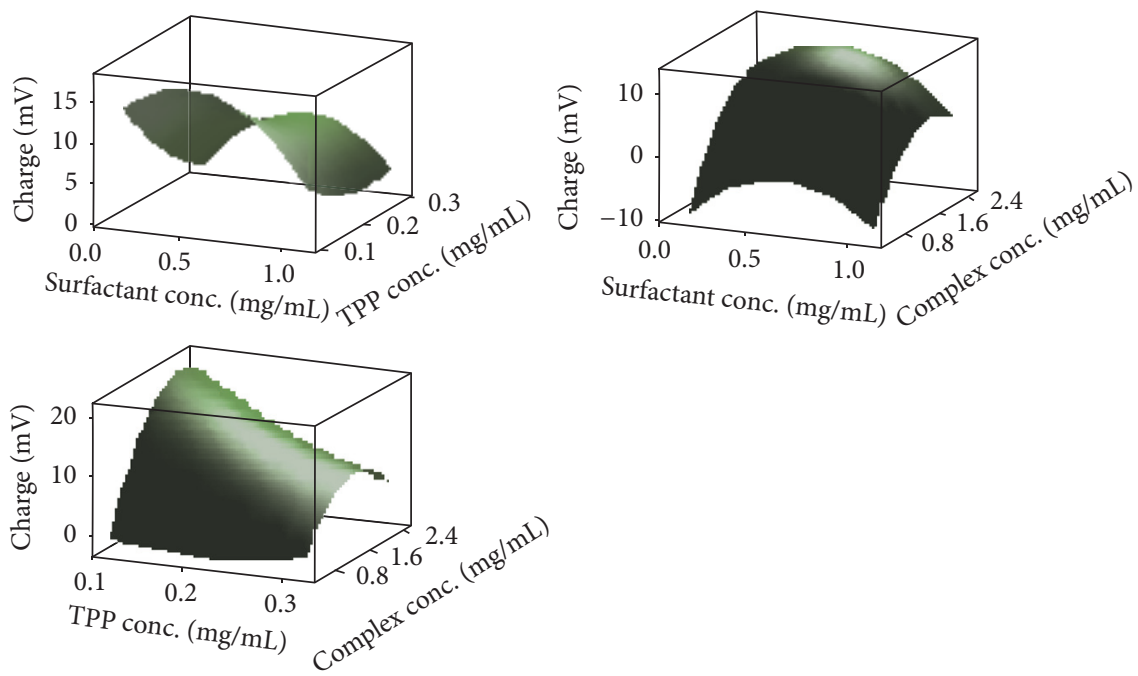

(b)
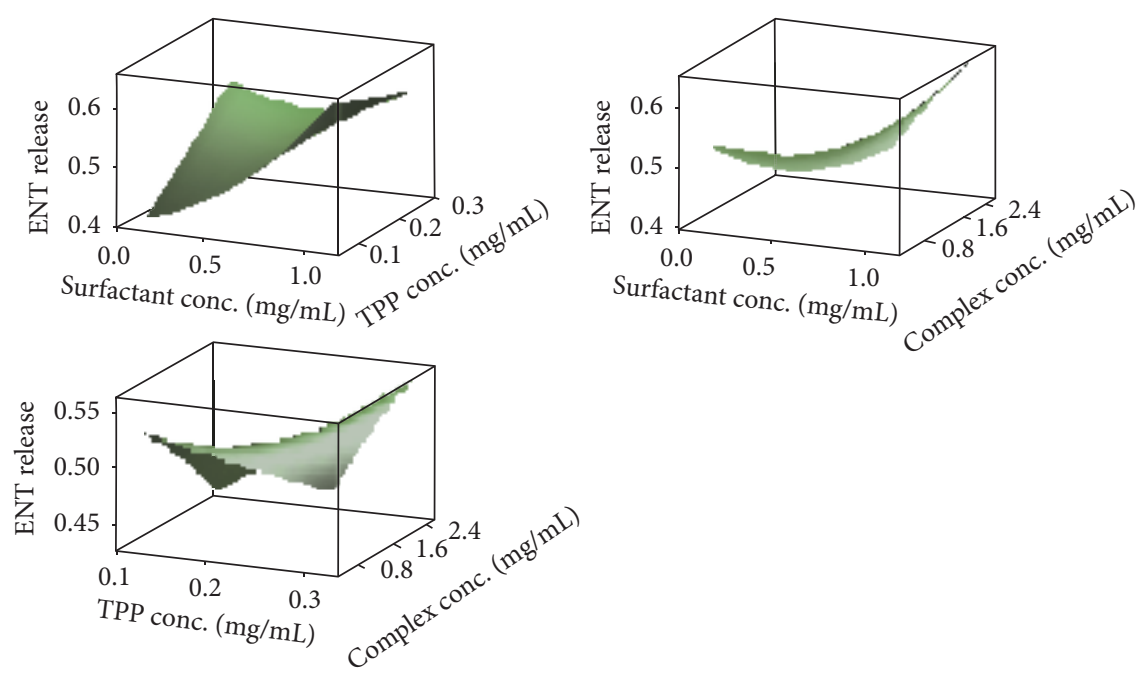

(c)

FIGURE 10: Surface plots showing the effects of polymer, TPP, and surfactant concentrations on (a) nanoparticle size, (b) surface charge, and (c) ENT release. 


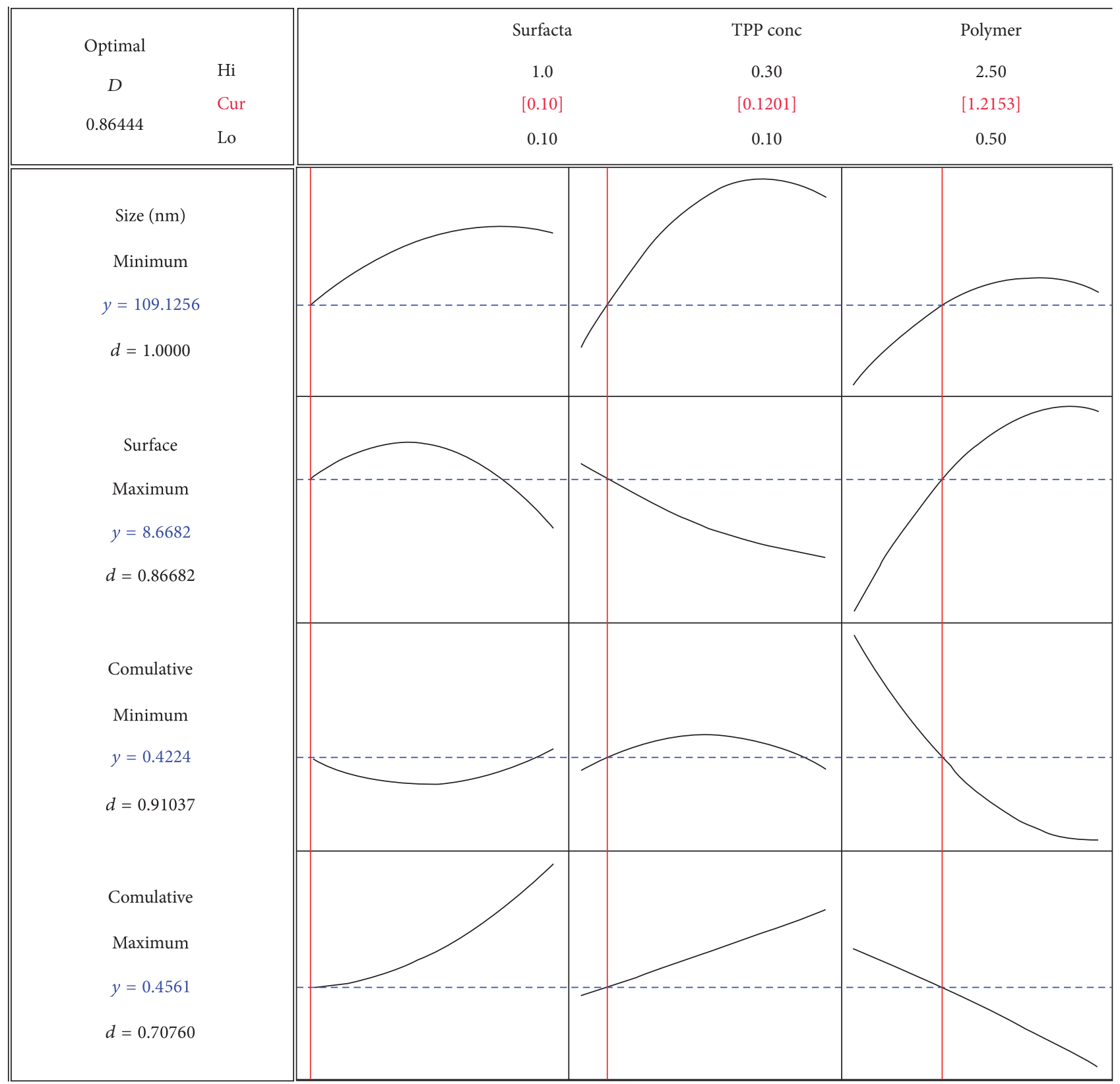

FIGURE 11: Response optimization plot showing the desirability value, the values of independent variables, and predicted values of the optimized nanoparticles.

inhibition, more than fourfold $(61.68 \%)$, was observed at nanoparticle concentration of $1000 \mu \mathrm{g} / \mathrm{mL}$ over the same period of incubation. An unpaired t-test and two-tailed $P$ values for native and endostatin-loaded nanoparticles when compared to the control untreated cells showed statistically significant differences at $P=0.0388$ and $P=0.0003$, respectively. Meanwhile, there is no significant difference between native and endostatin-loaded nanoparticles for 125, 250, and $500 \mu \mathrm{g} / \mathrm{mL}$ after 24 hours' treatments when compared to the control. However, longer exposure of KYSE-30 cells to longer incubation time may facilitate the inhibition potential of the drug-loaded nanoparticles relative to the native particles when compared to the control.
On a general note, encapsulation with nanocarriers reduces the toxicity of drug as they offer protection against degradation by RES $[52,53]$. In addition, encapsulation could also enable nanoparticles to target cell membranes by ensuring the release of drug close to the cell surface and increase the cellular uptake of nanoparticles in specific targeting studies which could enhance site-specific delivery of the nanocarriers in targeted cells thereby increasing their efficacy [54]. It is interesting to note that the doses of endostatin-loaded nanoparticles presented in this study, administered to the KYSE-30 cells to achieve the antiangiogenic drug levels presented in Figure 12, were in the range of $125-1000 \mu \mathrm{g} / \mathrm{mL}$ and were not expected to affect cell proliferation. The positively 


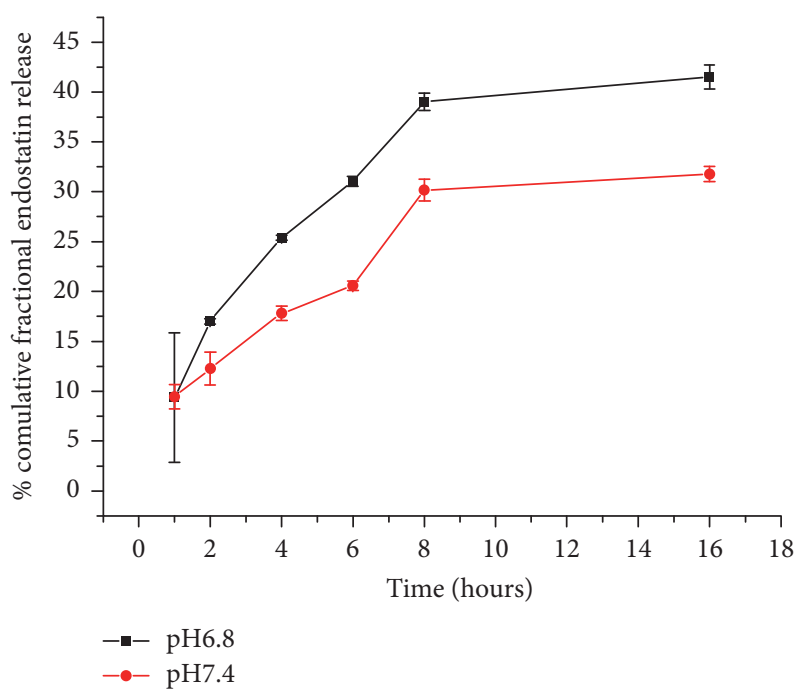

FIGURE 12: In vitro drug release kinetics of the optimized endostatinloaded nanoparticle system.

charged surface of the designed nanocargo, as presented in Figure 4(b), could have facilitated direct binding to the negatively charged surface of KYSE-30 cells having a typical tumor cell surface [26]. Similarly, the shielding effect of the nanoparticles' surface by PEG could have modulated the release of endostatin within the nanoparticle matrix thereby increasing its antiangiogenic efficacy on the treated cells.

Formation of new blood vessels and cell proliferation are potent indicators of angiogenesis $[55,56]$ which are key for tumor cell survival. Therefore, our novel nanosystem could serve as a potential nanocargo for the delivery of endostatin and other related antiangiogenic cancer therapeutics for effective management of SCC.

\section{Conclusions}

The study confirmed successful conjugation, formulation, and optimization of a PEGylated CHT-g-PEI-based nanosystem loaded with endostatin as a potential delivery vehicle for endostatin. The concentration of $\mathrm{CHT}$ as the main polymer as well as the cross linker concentration was a fundamental factor that modulates the BSA/endostatin encapsulation, release, and swelling behaviour. More so, addition of PEI onto the CHT moiety increased the overall amine protonation of the grafted polymer network at lower $\mathrm{pH}$ value and thus impacted positively on nanoparticle swelling and in vitro BSA/endostatin release. Positively charged spherical nanoparticles were synthesized with a varying $\mathrm{BSA} / \mathrm{endostatin}$ release profile at tumor $\mathrm{pH}$ and normal physiological $\mathrm{pH}$ conditions were observed, due to instantaneous swelling and shrinking behaviour of the nanosystem, respectively. The positively charged surface of these nanoparticles could be harnessed for adhesion to the negatively charged surface of many tumor cells including OSCC. The polymer conjugate was validated to be nontoxic to established squamous cell oesophageal carcinoma cell line (KYSE-30). Furthermore, encapsulation of endostatin

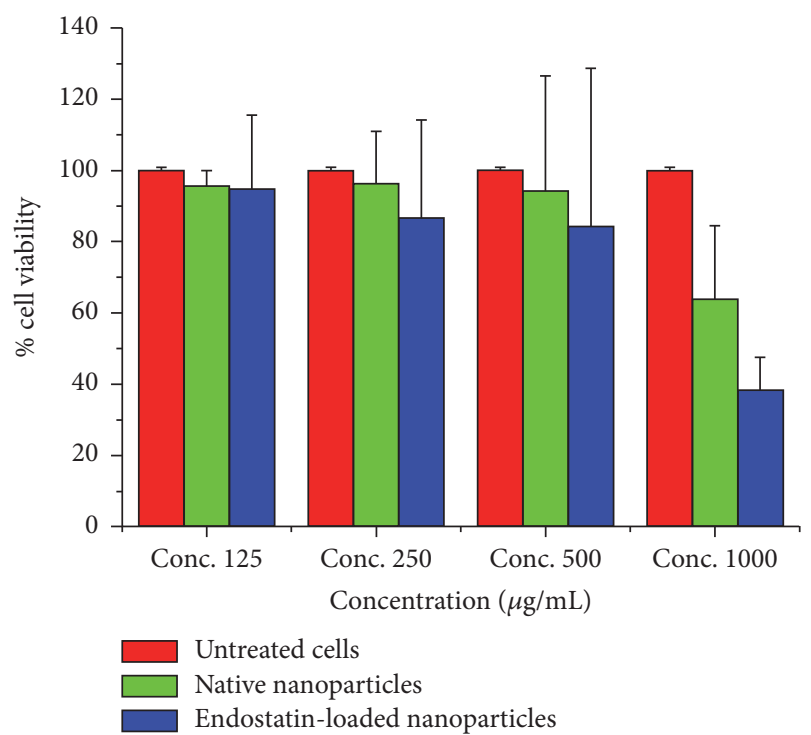

FIGURE 13: Cell viability/proliferation of treated and untreated oesophageal squamous cell carcinoma (KYSE-30) after 24-hour exposure to the nanoformulations at varying polymer concentrations. An unpaired t-test, two-tailed $P$ values for native and endostatin-loaded nanoparticles when compared to the control untreated cells showed statistically significant differences at $P=$ 0.0388 and $P=0.0003$, respectively. Meanwhile, there is no significant difference between native and endostatin-loaded nanoparticles for 125 , 250, and $500 \mu \mathrm{g} / \mathrm{mL}$ after 24-hour treatment.

in the nanoconstruct showed efficient cytotoxicity against cell proliferation and angiogenesis in a tumor model in vitro. This study validates the potential use of endostatinloaded CHT-g-PEI-PEG- $\mathrm{NH}_{2}$ nanoparticles in OSCC in vitro; further in vivo experiments are necessary to confirm the preclinical potential of this system. Further, functionalizing this nanoconstruct with OSCC specific biomarkers could enhance direct targeting of endostatin as a potent endogenous antiangiogenic inhibitor in OSCC management both in vitro and in vivo.

\section{Conflicts of Interest}

The authors confirm that there are no conflicts of interest.

\section{Acknowledgments}

This work was funded by the National Research Foundation (NRF) of South Africa and the Cancer Research Association of South Africa (CANSA).

\section{References}

[1] A. S. Adebowale, Y. E. Choonara, P. Kumar, L. C. Du Toit, and V. Pillay, "Functionalized nanocarriers for enhanced bioactive delivery to squamous cell carcinomas: targeting approaches and related biopharmaceutical aspects," Current Pharmaceutical Design, vol. 21, no. 22, pp. 3167-3180, 2015. 
[2] S. Hu and Y. Zhang, "Endostar-loaded PEG-PLGA nanoparticles: in vitro and in vivo evaluation," International Journal of Nanomedicine, vol. 5, no. 1, pp. 1039-1048, 2010.

[3] N. Nishiyama and K. Kataoka, "Current state, achievements, and future prospects of polymeric micelles as nanocarriers for drug and gene delivery," Pharmacology and Therapeutics, vol. 112, no. 3, pp. 630-648, 2006.

[4] V. P. Torchilin, "Targeted pharmaceutical nanocarriers for cancer therapy and imaging," The AAPS Journal, vol. 9, no. 2, pp. E128-E147, 2007.

[5] J. Folkman, "Tumor angiogenesis: therapeutic implications," The New England Journal of Medicine, vol. 285, no. 21, pp. 1182$1186,1971$.

[6] J. Folkman, "What is the evidence that tumors are angiogenesis dependent?" Journal of the National Cancer Institute, vol. 82, no. 1, pp. 4-6, 1990.

[7] M. Zheng, "Endostatin derivative angiogenesis inhibitors," Chinese Medical Journal (England), vol. 122, pp. 1947-1951, 2009.

[8] J. Folkman, "Antiangiogenesis in cancer therapy-Endostatin and its mechanisms of action," Experimental Cell Research, vol. 312, no. 5, pp. 594-607, 2006.

[9] R. S. Herbst, A. T. Lee, H. T. Tran, and J. L. Abbruzzese, “Clinical studies of angiogenesis inhibitors: the University of Texas Md Anderson Center Trial of Human Endostatin," Current Oncology Reports, vol. 3, no. 2, pp. 131-140, 2001.

[10] Y.-M. Kim, S. Hwang, Y.-M. Kim et al., "Endostatin blocks vascular endothelial growth factor-mediated signaling via direct interaction with KDR/Flk-1, Journal of Biological Chemistry, vol. 277, no. 31, pp. 27872-27879, 2002.

[11] B. Qiu, M. Ji, X. Song et al., "Co-delivery of docetaxel and endostatin by a biodegradable nanoparticle for the synergistic treatment of cervical cancer," Nanoscale Research Letters, vol. 7, article 666, 2012.

[12] R. S. Tiğlı Aydin and M. Pulat, "5-fluorouracil encapsulated chitosan nanoparticles for $\mathrm{pH}$-stimulated drug delivery: evaluation of controlled release kinetics," Journal of Nanomaterials, vol. 2012, Article ID 313961, 10 pages, 2012.

[13] J. C. Y. Ip, J. M. Y. Ko, V. Z. Yu et al., "A versatile orthotopic nude mouse model for study of esophageal squamous cell carcinoma," BioMed Research International, vol. 2015, Article ID 910715, 10 pages, 2015.

[14] M. Ogris, G. Walker, T. Blessing, R. Kircheis, M. Wolschek, and E. Wagner, "Tumor-targeted gene therapy: strategies for the preparation of ligand-polyethylene glycol-polyethylenimine/ DNA complexes," Journal of Controlled Release, vol. 91, no. 1-2, pp. 173-181, 2003.

[15] S. M. Zou, P. Erbacher, J. S. Remy, and J. P. Behr, "Systemic linear polyethylenimine (L-PEI)-mediated gene delivery in the mouse," The Journal of Gene Medicine, vol. 2, no. 2, pp. 128-134, 2000.

[16] L. Jia, Z. Li, D. Zhang et al., "Redox-responsive catiomer based on PEG-ss-chitosan oligosaccharide-ss-polyethylenimine copolymer for effective gene delivery," Polymer Chemistry, vol. 4, no. 1, pp. 156-165, 2013.

[17] J.-Q. Gao, Q.-Q. Zhao, T.-F. Lv et al., "Gene-carried chitosanlinked-PEI induced high gene transfection efficiency with low toxicity and significant tumor-suppressive activity," International Journal of Pharmaceutics, vol. 387, no. 1-2, pp. 286-294, 2010.

[18] H.-L. Jiang, J.-T. Kwon, E.-M. Kim et al., "Galactosylated poly(ethylene glycol)-chitosan-graft-polyethylenimine as a gene carrier for hepatocyte-targeting," Journal of Controlled Release, vol. 131, no. 2, pp. 150-157, 2008.

[19] K. Sarkar, M. Debnath, and P. P. Kundu, "Preparation of low toxic fluorescent chitosan-graft-polyethyleneimine copolymer for gene carrier," Carbohydrate Polymers, vol. 92, no. 2, pp. 2048-2057, 2013.

[20] H. Lu, Y. Dai, L. Lv, and H. Zhao, "Chitosan-graft-polyethylenimine/DNA nanoparticles as novel non-viral gene delivery vectors targeting osteoarthritis," PLoS ONE, vol. 9, no. 1, Article ID e84703, 2014.

[21] A. Mehrotra, R. C. Nagarwal, and J. K. Pandit, "Fabrication of lomustine loaded chitosan nanoparticles by spray drying and in vitro cytostatic activity on human lung cancer cell line L132," Journal of Nanomedicine and Nanotechnology, vol. 1, no. 1, 2010.

[22] H. Chen, S. Cui, Y. Zhao, C. Zhang, S. Zhang, and X. Peng, "Grafting chitosan with polyethylenimine in an ionic liquid for efficient gene delivery," PLoS ONE, vol. 10, no. 4, Article ID e0121817, 2015.

[23] M. M. AbdElhady, "Preparation and characterization of chitosan/zinc oxide nanoparticles for imparting antimicrobial and UV protection to cotton fabric," International Journal of Carbohydrate Chemistry, vol. 2012, Article ID 840591, 6 pages, 2012.

[24] B. Zhou, M. Shen, I. Bányai, and X. Shi, "Structural characterization of PEGylated polyethylenimine-entrapped gold nanoparticles: an NMR study," The Analyst, vol. 141, no. 18, pp. 5390-5397, 2016.

[25] X. Zou, X. Zhao, L. Ye, Q. Wang, and H. Li, "Preparation and drug release behavior of $\mathrm{pH}$-responsive bovine serum albumin-loaded chitosan microspheres," Journal of Industrial and Engineering Chemistry, vol. 21, pp. 1389-1397, 2015.

[26] B. Chen, W. Le, Y. Wang et al., "Targeting negative surface charges of cancer cells by multifunctional nanoprobes," Theranostics, vol. 6, no. 11, pp. 1887-1898, 2016.

[27] I. Dobrzyńska, E. Skrzydlewska, and Z. A. Figaszewski, "Changes in electric properties of human breast cancer cells," Journal of Membrane Biology, vol. 246, no. 2, pp. 161-166, 2013.

[28] B. Szachowicz-Petelska, I. Dobrzyska, S. Sulkowski, and A. Z. Figaszewski, "Characterization of the cell membrane during cancer transformation," in Colorectal Cancer Biology-From Genes to Tumor, R. Ettarh, Ed., InTech, 2012.

[29] S. Latha, P. Selvamani, K. Naveenkumar, P. Ayyanar, and T. Silambarasi, "Formulation and evaluation of capecitabine nanoparticles for cancer therapy," International Journal of Biological and Pharmaceutical Research, vol. 3, pp. 477-487, 2012.

[30] C. He, Y. Hu, L. Yin, C. Tang, and C. Yin, "Effects of particle size and surface charge on cellular uptake and biodistribution of polymeric nanoparticles," Biomaterials, vol. 31, no. 13, pp. 36573666, 2010.

[31] H. Jiang, Y. Kim, R. Arote et al., "Chitosan-graft-polyethylenimine as a gene carrier," Journal of Controlled Release, vol. 117, no. 2, pp. 273-280, 2007.

[32] G. Sharma, D. T. Valenta, Y. Altman et al., "Polymer particle shape independently influences binding and internalization by macrophages," Journal of Controlled Release, vol. 147, no. 3, pp. 408-412, 2010.

[33] A. Verma and F. Stellacci, "Effect of surface properties on nanoparticle-cell interactions," Small, vol. 6, no. 1, pp. 12-21, 2010. 
[34] C. Sacchetti, M. Artusi, P. Santi, and P. Colombo, "Caffeine microparticles for nasal administration obtained by spray drying," International Journal of Pharmaceutics, vol. 242, no. 1-2, pp. 335-339, 2002.

[35] E. C. Dreaden, L. A. Austin, M. A. MacKey, and M. A. ElSayed, "Size matters: gold nanoparticles in targeted cancer drug delivery," Therapeutic Delivery, vol. 3, no. 4, pp. 457-478, 2012.

[36] F. Ikomi, G. K. Hanna, and G. W. Schmid-Schönbein, "Size- and surface-dependent uptake of colloid particles into the lymphatic system," Lymphology, vol. 32, no. 3, pp. 90-102, 1999.

[37] G. W. Vandenberg, C. Drolet, S. L. Scott, and J. De la Noüe, "Factors affecting protein release from alginate-chitosan coacervate microcapsules during production and gastric/intestinal simulation," Journal of Controlled Release, vol. 77, no. 3, pp. 297307, 2001.

[38] G. Mukhopadhyay, "HPLC analysis on separation of BSA from dilute solution," Endocrine Abstracts, vol. 31, p. 40, 2014.

[39] G. Mukhopadhyay, T. Panja, and S. Mazumder et al., "HPLC analysis on separation of BSA from dilute solution," International Journal of Pharmaceutical Engineering, vol. 1, no. 1, pp. $5-7,2012$.

[40] L. E. Gerweck and K. Seetharaman, "Cellular pH gradient in tumor versus normal tissue: potential exploitation for the treatment of cancer," Cancer Research, vol. 56, no. 6, pp. 11941198, 1996.

[41] F. Alexis, E. Pridgen, L. K. Molnar, and O. C. Farokhzad, "Factors affecting the clearance and biodistribution of polymeric nanoparticles," Molecular Pharmaceutics, vol. 5, no. 4, pp. 505515,2008

[42] J. V. Jokerst, T. Lobovkina, R. N. Zare, and S. S. Gambhir, "Nanoparticle PEGylation for imaging and therapy," Nanomedicine, vol. 6, no. 4, pp. 715-728, 2011.

[43] J.-W. Yoo, E. Chambers, and S. Mitragotri, "Factors that control the circulation time of nanoparticles in blood: challenges, solutions and future prospects," Current Pharmaceutical Design, vol. 16, no. 21, pp. 2298-2307, 2010.

[44] S. Mavuso, Y. E. Choonara, T. Marimuthu et al., "A dual $\mathrm{pH} /$ Redox responsive copper-ligand nanoliposome bioactive complex for the treatment of chronic inflammation," International Journal of Pharmaceutics, vol. 509, no. 1-2, pp. 348-359, 2016.

[45] K. Sharma, O. Y. Zolotarskaya, K. J. Wynne, and H. Yang, "Poly(ethylene glycol)-armed hyperbranched polyoxetanes for anticancer drug delivery," Journal of Bioactive and Compatible Polymers, vol. 27, no. 6, pp. 525-539, 2012.

[46] K. R. Vega-Villa, J. K. Takemoto, J. A. Yáñez, C. M. Remsberg, M. L. Forrest, and N. M. Davies, "Clinical toxicities of nanocarrier systems," Advanced Drug Delivery Reviews, vol. 60, no. 8, pp. 929-938, 2008.

[47] A. Abdollahi, P. Hahnfeldt, C. Maercker et al., "Endostatin's antiangiogenic signaling network," Molecular Cell, vol. 13, no. 5, pp. 649-663, 2004.

[48] M. S. O’Reilly, T. Boehm, Y. Shing et al., "Endostatin: an endogenous inhibitor of angiogenesis and tumor growth," Cell, vol. 88 , no. 2, pp. 277-285, 1997.

[49] M. Dhanabal, R. Ramchandran, M. J. F. Waterman et al., "Endostatin induces endothelial cell apoptosis," Journal of Biological Chemistry, vol. 274, no. 17, pp. 11721-11726, 1999.
[50] T. Hammady, J.-M. Rabanel, R. S. Dhanikula, G. Leclair, and P. Hildgen, "Functionalized nanospheres loaded with antiangiogenic drugs: cellular uptake and angiosuppressive efficacy," European Journal of Pharmaceutics and Biopharmaceutics, vol. 72, no. 2, pp. 418-427, 2009.

[51] Y. Ling, Y. Yang, N. Lu et al., "Endostar, a novel recombinant human endostatin, exerts antiangiogenic effect via blocking VEGF-induced tyrosine phosphorylation of KDR/Flk1 of endothelial cells," Biochemical and Biophysical Research Communications, vol. 361, no. 1, pp. 79-84, 2007.

[52] Z. Zhang and S.-S. Feng, "The drug encapsulation efficiency, in vitro drug release, cellular uptake and cytotoxicity of paclitaxelloaded poly(lactide)-tocopheryl polyethylene glycol succinate nanoparticles," Biomaterials, vol. 27, no. 21, pp. 4025-4033, 2006.

[53] L. Gonzalez-Fajardo, L. H. Mahajan, D. Ndaya et al., "Reduced in vivo toxicity of doxorubicin by encapsulation in cholesterolcontaining self-assembled nanoparticles," Pharmacological Research, vol. 107, pp. 93-101, 2016.

[54] C. S. Cho, K. Y. Cho, I. K. Park et al., "Receptor-mediated delivery of all trans-retinoic acid to hepatocyte using poly(Llactic acid) nanoparticles coated with galactose-carrying polystyrene," Journal of Controlled Release, vol. 77, no. 1-2, pp. 7-15, 2001.

[55] A. M. Goodwin, "In vitro assays of angiogenesis for assessment of angiogenic and anti-angiogenic agents," Microvascular Research, vol. 74, no. 2-3, pp. 172-183, 2007.

[56] Y. Yokoyama and S. Ramakrishnan, "Addition of an aminopeptidase N-binding sequence to human endostatin improves inhibition of ovarian carcinoma growth," Cancer, vol. 104, no. 2, pp. 321-331, 2005. 

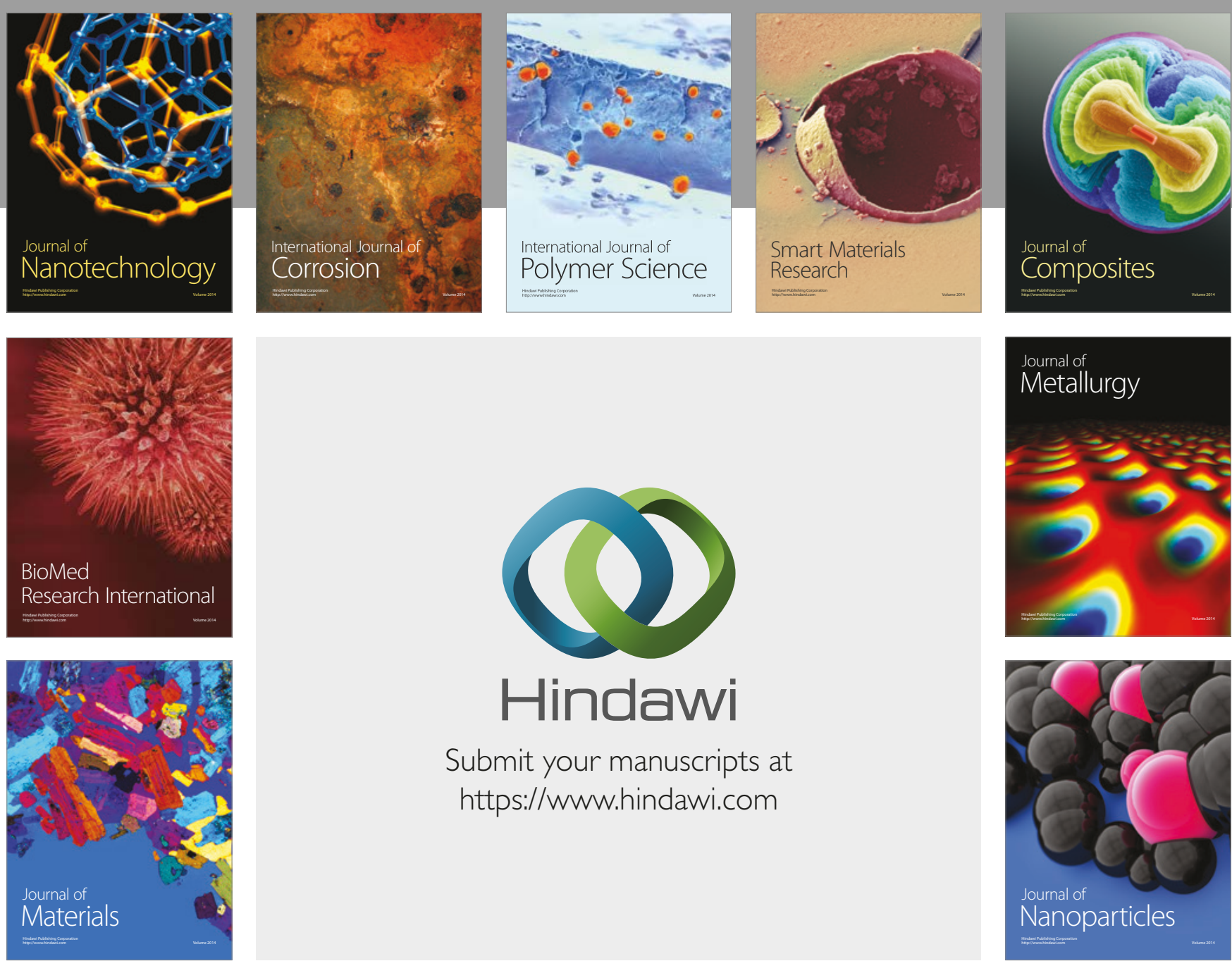

\section{Hindawi}

Submit your manuscripts at

https://www.hindawi.com
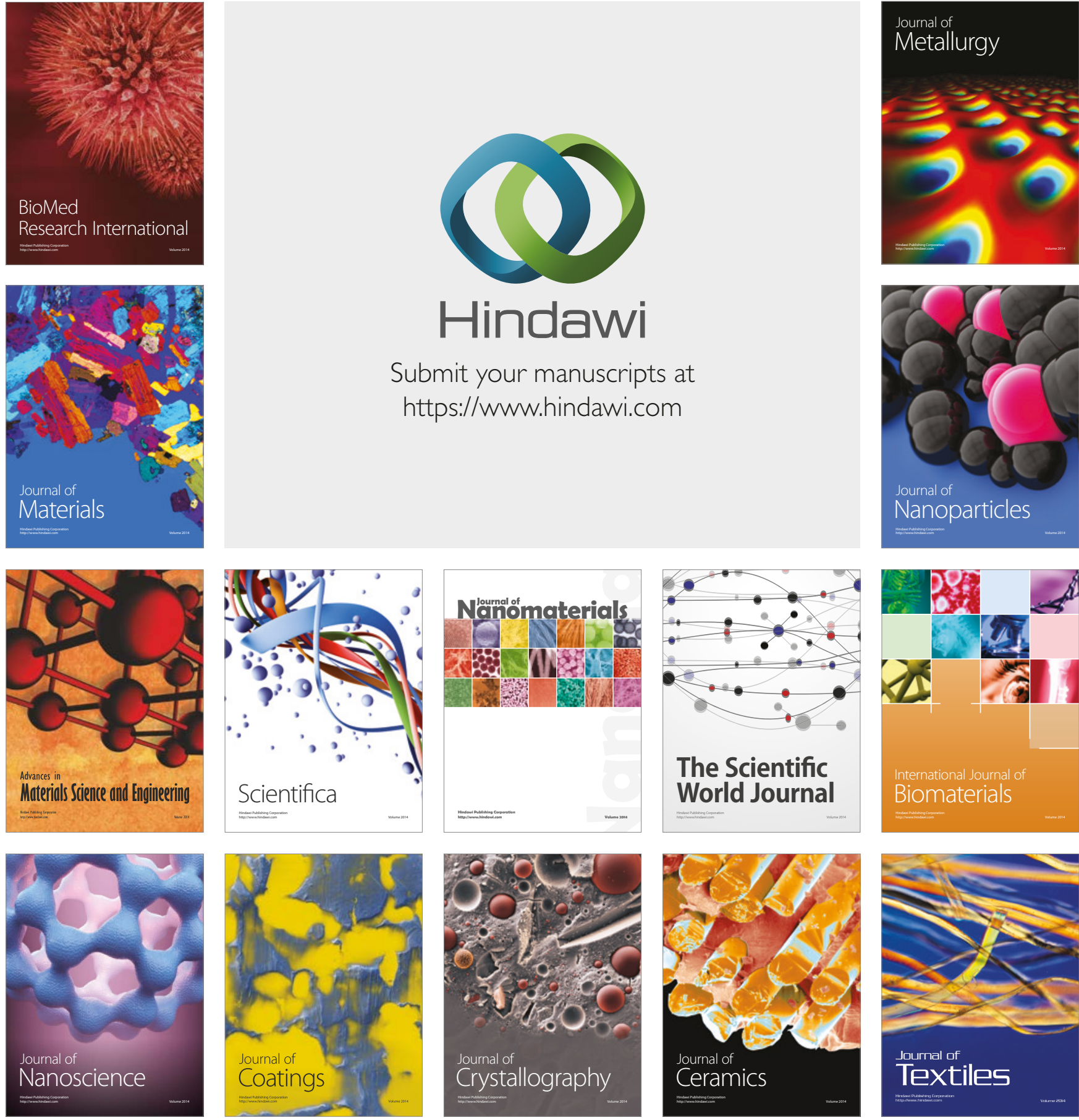

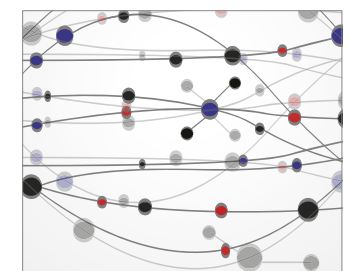

The Scientific World Journal
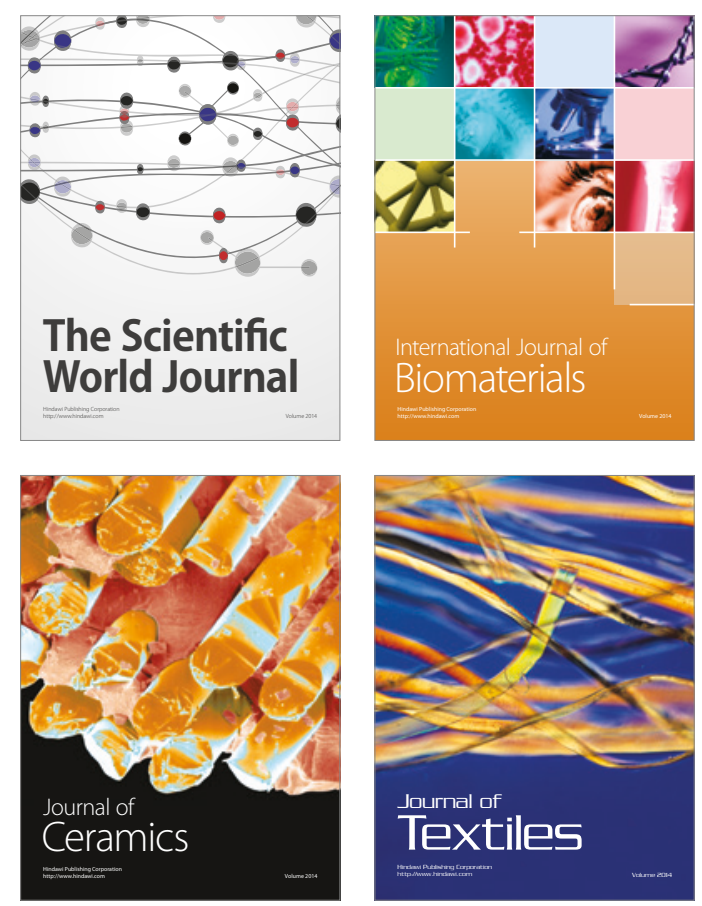